Key Words:

Tank 21 Blending, Jet Blending,

Turbulence Model, Settling Times, Salt Disposition Integration Project

Retention:

Permanent

\title{
Tank 21 and Tank 24 Blend and Feed Study: Blending Times, Settling Times, and Transfers
}

MAY 2012

Savannah River National Laboratory

Savannah River Nuclear Solutions

Aiken, SC 29808

Prepared for the U.S. Department of Energy Under

Contract Number DE-AC09-08SR22470

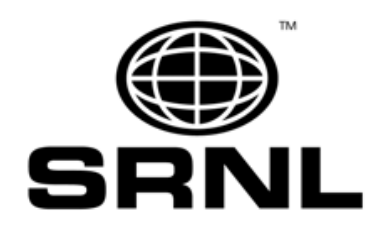




\section{DISCLAIMER}

This work was prepared under an agreement with and funded by the U.S. Government. Neither the U. S. Government or its employees, nor any of its contractors, subcontractors or their employees, makes any express or implied:

1. warranty or assumes any legal liability for the accuracy, completeness, or for the use or results of such use of any information, product, or process disclosed; or

2. representation that such use or results of such use would not infringe privately owned rights; or

3. endorsement or recommendation of any specifically identified commercial product, process, or service.

Any views and opinions of authors expressed in this work do not necessarily state or reflect those of the United States Government, or its contractors, or subcontractors.

Printed in the United States of America

Prepared for

U.S. Department of Energy 
Key Words:

Jet Mixing,

Turbulence Model

Retention:

Permanent

\section{Tank 21 and Tank 24 Blend and Feed Study: Blending Times, Settling Times, and Transfers}

S. Y. Lee, R. A. Leishear, and M. R. Poirier

MAY 2012

Savannah River National Laboratory

Savannah River Nuclear Solutions

Savannah River Site

Aiken, SC 29808 


\section{TABLE OF CONTENTS}

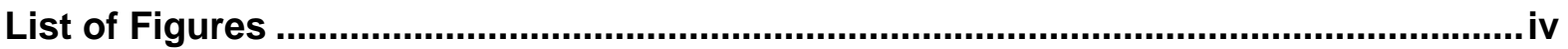

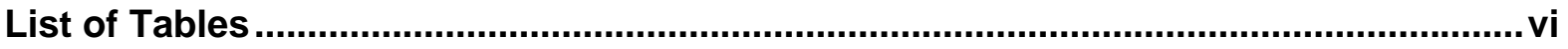

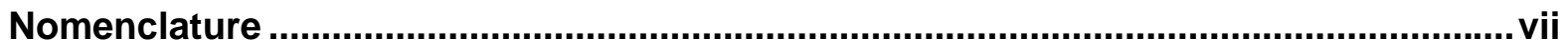

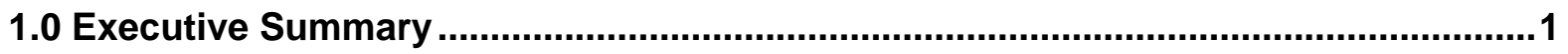

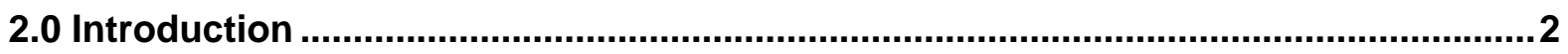

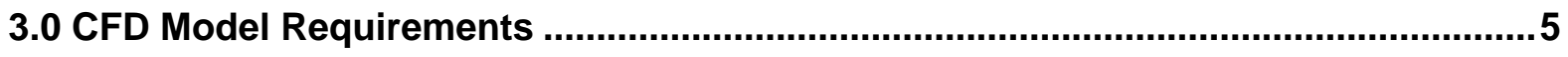

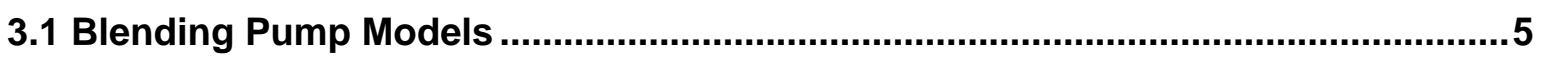

3.1.1 Blending Pump Installation and Operation............................................................... 5

3.1.2 Previous Research ............................................................................................................. 6

3.1.3 Present Research ..................................................................................................... 7

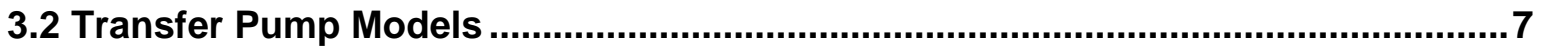

3.2.1 Acceptance Criteria.................................................................................................. 7

3.2.2 Tank 21 Transfer Pump Summary...................................................................... 8

3.2.3 Tank 24 Transfer Pump Summary.............................................................................. 8

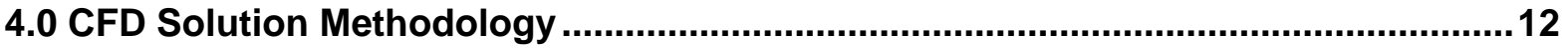

4.1 Blending Time CFD Model .................................................................................12

4.1.1 Governing Equations ...................................................................................................... 13

4.1.2 Tank 21 CFD Model.................................................................................................... 15

4.2 Transfer Pump CFD Model.............................................................................

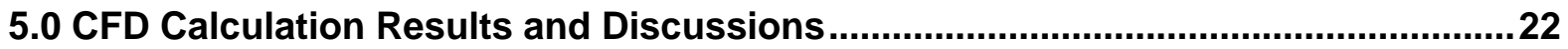

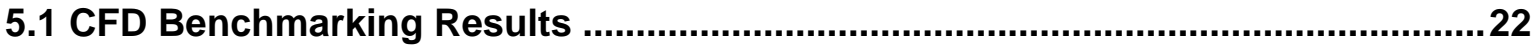

5.1.1 Literature Benchmarking Results for Blending........................................................ 22

5.1.2 Phase 1 and 2 Benchmarking Results for Velocity.................................................... 23

5.1.3 Phase 1 and 2 Benchmarking Results for Blending Times.................................... 23

5.2 CFD Performance, Modeling Results ..............................................................29

5.2.1 Blending Time Results ................................................................................................ 29

5.2.2 Transfer Pump Results ....................................................................................... 30

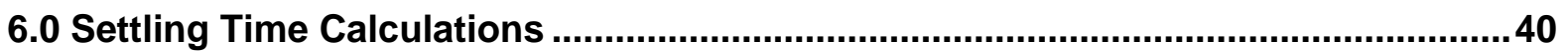

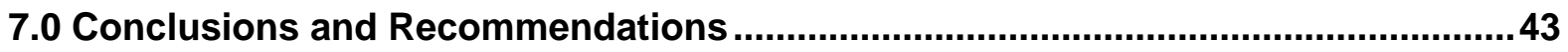

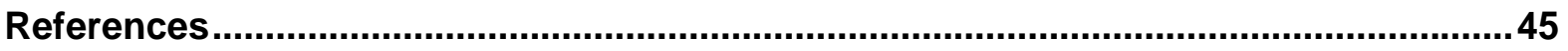




\section{LIST OF FIGURES}

Figure 1. Tank 21 Pump Installations 3

Figure 2: Tank 24 Pump Installations ...................................................................... 4

Figure 3. Modeling geometry used for the Tank 21 blending time calculations of the standard slurry pump with dual jets

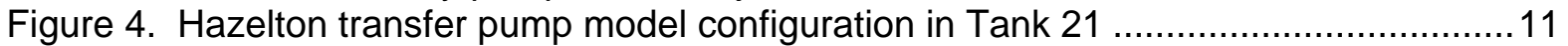

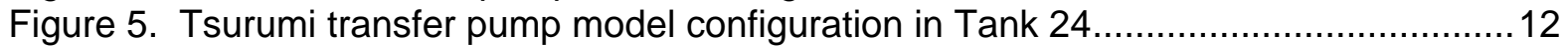

Figure 6 . Three dimensional modeling domain used for the blending calculations..............16

Figure 7. Computational domain and mesh nodes for the Tank 21 modeling domain $(4.2 \mathrm{x}$ $10^{6}$ meshes) ....................................................................................... 17

Figure 8. Computational domain for the Hazelton transfer pump model in Tank $21 \ldots \ldots \ldots . . .19$

Figure 9. Computational domain for the Tsurumi transfer pump model in Tank $24 \ldots \ldots \ldots . . .20$

Figure 10. Computational domain and mesh nodes for the Tank 21 Hazelton transfer pump modeling domain $\left(3.2 \times 10^{6}\right.$ meshes $)$...................................................2 21

Figure 11. Computational domain and mesh nodes for the Tank 24 Tsurumi transfer pump

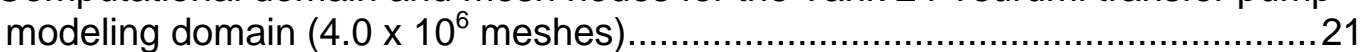

Figure 12 Tank A, geometry for the demonstration runs based on two different approaches of transient flow pattern and species transport calculations ...........................24

Figure 13. Fully developed flow patterns used as the initial flow conditions for the transient transport calculations using tracer species .................................................25

Figure 14. Lagrangian flow path lines from jet inlet to tank exit for fully developed flow

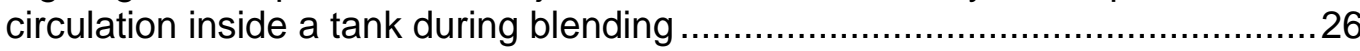

Figure 15. Comparison of transient time snapshots for flow patterns of species concentration at vertical central plane through the pump nozzle center line ( ${ }^{\star}$ Non-dimensionalized by equilibrium species concentration of $3.02 \times 10^{-4}$;

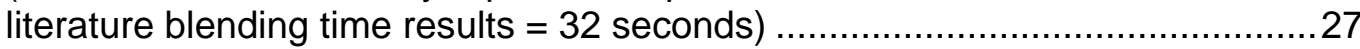

Figure 16. Benchmarking results of theoretical tank blending time compared to experimental test results [Ref. 9]

Figure 17. Benchmarking results of local fluid velocities compared to experimental test results [Ref. 9]

Figure 18. Steady state flow patterns at the discharge plane elevation of the slurry pump.31

Figure 19. Steady state flow distributions at the discharge plane elevation of the slurry

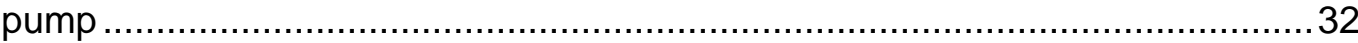

Figure 20. Lagrangian flow circulation patterns for fully developed flow circulation inside the tank

Figure 21. Transient concentrations at an observation point at the tank center and pump elevation

Figure 22. Transient maximum and minimum concentrations during blending operations in Tank 21

Figure 23. Comparison of the transient results for fluid velocity, energy dissipation rate, flow circulation patterns, and species concentration distributions at the slurry pump discharge elevation plane at the transient time of 5.5 minutes.

Figure 24. Transient non-dimensionalized concentration distributions on the pump discharge plane.

Figure 25. Typical flow patterns near the transfer pump inlet in Tank 21 as shown by Lagrangian integration along the fluid flow paths.

Figure 26. Flow patterns on the top surface of the sludge layer in Tank 24 (100 gpm flowrate) 
Figure 27. Flow rate distributions for Tank 21 (ft/sec) ......................................... 37

Figure 28. Typical flow patterns near the transfer pump inlet with solid plate in Tank 24 as shown by Lagrangian integration along the fluid flow paths

Figure 29. Flow patterns on the top surface of the sludge layer in Tank 21 (100 gpm transfer flowrate)

Figure 30. Flow rate distributions for Tank 24 (ft/sec)

Figure 31. Velocity profile for each pump along the tank radial center line at the top surface of the sludge layer

Figure 32. Settling velocity of sludge particles as a function of particle size and density ....41

Figure 33. Time for sludge particle to settle 345 Inches ............................................. 41

Figure 34. Time for sludge particle to settle 345 Inches ............................................ 42

Figure 35. Particle size of actual SRS sludge ............................................................. 42 


\section{LIST OF TABLES}

Table 1. Pump design and modeling parameters for slurry pump used for jet blending

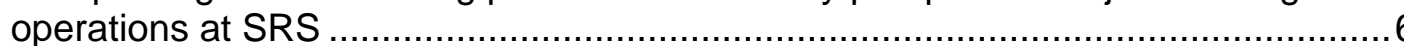

Table 2. Pump design and modeling parameters for Tank 21 and Tank 24 transfer pump

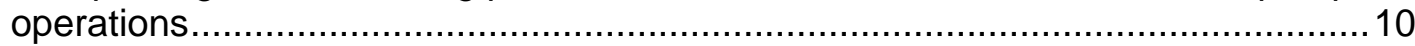

Table 3. Test conditions and literature mixing times [Ref. 15] for transient CFD calculations

Table 4. Comparison of maximum velocity magnitudes on the top sludge surface 39 


\section{NOMENCLATURE}

\begin{tabular}{|c|c|}
\hline A & Area \\
\hline $\mathrm{C}$ & Concentration or constant for equation \\
\hline $\mathrm{C}_{1}$ & Constant for equation \\
\hline $\mathrm{C}_{2}$ & Constant for equation \\
\hline $\mathrm{C}_{\mathrm{eq}}$ & Equilibrium concentration \\
\hline $\mathrm{C}_{\mu}$ & Constant used in Eq. (2) \\
\hline $\mathrm{D}$ & Tank diameter \\
\hline$D_{v}$ & Molecular diffusion coefficient for species \\
\hline $\mathrm{d}_{\mathrm{o}}$ & Jet nozzle diameter \\
\hline$d_{p}$ & Particle diameter \\
\hline$g$ & Gravitational acceleration \\
\hline $\mathrm{h}_{\mathrm{I}}$ & Liquid height \\
\hline$\vec{J}_{v}$ & Diffusion flux of species \\
\hline$k$ & Turbulent kinetic energy per unit mass \\
\hline I & Liter \\
\hline $\mathrm{m}$ & Total mass flow rate \\
\hline $\mathrm{ml}$ & milliliter (= 0.001 liter) \\
\hline $\mathrm{m}_{\mathrm{o}}$ & Mass flow rate at jet inlet \\
\hline$P$ & Production in turbulent kinetic energy transport \\
\hline S & Density ratio of particle to fluid \\
\hline $\mathrm{Sc}_{\mathrm{t}}$ & Turbulent Schmidt number \\
\hline $\mathrm{S}_{\mathrm{v}}$ & Source term in species transport equation \\
\hline $\mathrm{t}$ & Time \\
\hline$t_{d}$ & Kolmogorov time \\
\hline$t_{m}$ & Mixing time in Eq. (2) \\
\hline$t_{\text {blend }}$ & Blending time \\
\hline $\mathrm{U}_{\mathrm{o}}$ & Velocity at jet inlet \\
\hline U & Local velocity along the jet discharge direction \\
\hline$\vec{v}$ & Local velocity vector \\
\hline $\mathrm{u}_{\mathrm{i}}$ & $\begin{array}{l}\text { Local turbulent fluctuation velocity ( } \mathrm{i}=1 \text { for } \mathrm{x} \text {-axis, } \mathrm{i}=2 \text { for } \mathrm{y} \text {-axis, } \mathrm{i}=3 \text { for } \mathrm{z} \text { - } \\
\text { axis) }\end{array}$ \\
\hline$<>$ & Time-averaging symbol for a parameter inside a sharp bracket \\
\hline $\mathrm{V}_{\mathrm{rms}}$ & Root-mean-square velocity \\
\hline $\mathrm{v}_{\mathrm{s}}$ & Settling velocity \\
\hline $\mathrm{x}$ & Local distance along the $x$-axis \\
\hline $\mathrm{Y}_{\mathrm{v}}$ & Tracer mass fraction of the mixture at a local point \\
\hline$\varepsilon$ & Turbulent energy dissipation rate per unit mass \\
\hline$\varepsilon_{m}$ & Relative error \\
\hline$\rho$ & Fluid density \\
\hline$\lambda$ & Turbulent length scale \\
\hline$\lambda_{\text {dif }}$ & Diffusion length \\
\hline$\mu_{t}$ & Turbulent dynamic viscosity $\left(=\rho v_{t}\right)$ \\
\hline$v$ & Kinematic viscosity \\
\hline$v_{\mathrm{t}}$ & Turbulent eddy diffusion coefficient \\
\hline $\operatorname{Re}$ & Reynolds number \\
\hline $\mathrm{Re}_{\text {jet }}$ & Reynolds number based on jet operating conditions \\
\hline
\end{tabular}


$\mathrm{Re}_{\mathrm{p}} \quad$ Reynolds number based on particle diameter and settling velocity $\left(=\mathrm{d}_{\mathrm{p}} \mathrm{v}_{\mathrm{s}} / v\right)$

SDI

SRS

SRNL

SWPF

CFD

FLUENT

wt
Salt Disposition Integration

Savannah River Site

Savannah River National Laboratory

Salt Waste Processing Facility

Computational Fluid Dynamics

CFD software code

Weight 


\subsection{EXECUTIVE SUMMARY}

The Salt Disposition Integration (SDI) portfolio of projects provides the infrastructure within existing Liquid Waste facilities to support the startup and long term operation of the Salt Waste Processing Facility (SWPF). Within SDI, the Blend and Feed Project will equip existing waste tanks in the Tank Farms to serve as Blend Tanks where salt solutions of up to 1.2 million gallons will be blended in 1.3 million gallon tanks and qualified for use as feedstock for SWPF. In particular, Tanks 21 and 24 are planned to be used for blending and transferring to the SDI feed tank. These tanks were evaluated here to determine blending times, to determine a range of settling times for disturbed sludge, and to determine that the SWPF Waste Acceptance Criteria that less than $1200 \mathrm{mg} / \mathrm{liter}$ of solids will be entrained in salt solutions during transfers from the Tank 21 and Tank 24 will be met.

Overall conclusions for Tank 21 and Tank 24 operations include:

1) Experimental correction factors were applied to CFD (computational fluid dynamics) models to establish blending times between approximately two and five hours. As shown in Phase 2 research, blending times may be as much as ten times greater, or more, if lighter fluids are added to heavier fluids (i.e., water added to salt solution). As the densities of two salt solutions converge this effect may be minimized, but additional confirmatory research was not performed.

2) At the current sludge levels and the presently planned operating heights of the transfer pumps, solids entrainment will be less than $1200 \mathrm{mg} /$ liter, assuming a conservative, slow settling sludge simulant.

3) Based on theoretical calculations, particles in the density range of 2.5 to $5.0 \mathrm{~g} / \mathrm{mL}$ must be greater than $2-4 \mu \mathrm{m}$ in diameter to ensure they settle adequately in 30-60 days to meet the SWPF feed criterion ( $<1200 \mathrm{mg} / \mathrm{l})$.

4) Experimental tests with sludge batch 6 simulant and field turbidity data from a recent Tank 21 mixing evolution suggest the solid particles have higher density and/or larger size than indicated by previous analysis of SRS sludge and sludge simulants.

5) Tank 21 waste characterization, laboratory settling tests, and additional field turbidity measurements during mixing evolutions are recommended to better understand potential risk for extended (> 60 days) settling times in Tank 21. 


\subsection{INTRODUCTION}

Scaled pump and mixing evaluations are being used for the Blend and Feed Key Scope within the SDI Portfolio of Projects. Phase 1 and Phase 2 modeling and experimental testing were used to recommend blender pump and transfer pump configurations, to determine blending times and transfer pump positioning for Type IIIA, radioactive liquid waste storage tanks, with and without cooling coils, using pilot scale experimental models and CFD models (Leishear, et al. [1-6]). Changes in Liquid Waste System Planning led to selection of Type IV construction waste tanks (Tank 21 and Tank 24) as blend tanks for preparation of initial Salt Waste Processing Facility feed batches. A significant difference between Type IV and Type IIIA tanks is the lack of a central roof support column and lack of cooling coils. Tank 21 has existing Sulzer Bingham slurry pumps installed as well as an existing Hazelton Transfer Pump. Tank 24 will use a modified Tsurumi transfer pump and will have a new Submersible Blending Pump (SBP) installed to provide blending capability. The Blend and Feed Project desires to evaluate using the existing Sulzer Bingham slurry pump in Tank 21 for blending, the existing Hazelton pump in Tank 21 for transfers, and the modified Tsurumi pump for transfers in Tank 24. For the research considered here, Fluent ${ }^{\circledR}$ CFD calculations (computational fluid dynamics) and other calculations were performed, where experimental results and equipment were not used in this phase of research.

For this work, CFD models were used to predict blending times in tanks to mix the tank contents. Disturbance of the settled sludge on the tank bottom is permitted, and estimates for the time required for different size sludge particles to settle was estimated by calculations, using Phase 1 and Phase 2 SDI data and other SRS sludge data. The exact settling times will be indeterminate, since sludge properties and volumes in Tanks 21 and 24 are unknown. Required clearances between transfer pumps and the settled sludge layer were determined from single phase CFD models, where velocities to disturb sludge were experimentally determined in Phase 2 testing, and a slow settling sludge simulant was used to experimentally model the sludge in liquid radioactive waste storage tanks.

With respect to transfer pump effects on sludge disturbance (i.e., entrainment), both the Hazelton and Tsurumi pumps were considered, and sludge properties were conservatively assumed for a low viscosity sludge identified in Phase 2 research. Only the transfer pump configuration and distance to the sludge layer was modeled, since the tank wall and other pumps will have a negligible effect on these CFD models.

In short, the deliverables are:

1) A CFD model for the blending time in Tank 21.

2) A prediction of the blending time in Tank 24, based on Phase 2 testing.

3) A predicted clearance of the Tank 21 Transfer pump, using a new CFD model and sludge material properties and acceptance criterion from Phase 2 testing, to avoid excessive (>1200 mg/l) solids entrainment.

4) A predicted clearance of the Tank 24 Transfer pump, using a new CFD model and sludge material properties and acceptance criterion from Phase 2 testing, to avoid excessive (>1200 mg/l) solids entrainment.

5) An estimate of the sludge settling time in Tank 21 based on particle sizes and approximated densities.

6) If the Submersible blender pump installed in Tank 24 meets the installation recommendations specified in the Phase 2 report, sludge disturbance is not expected. 


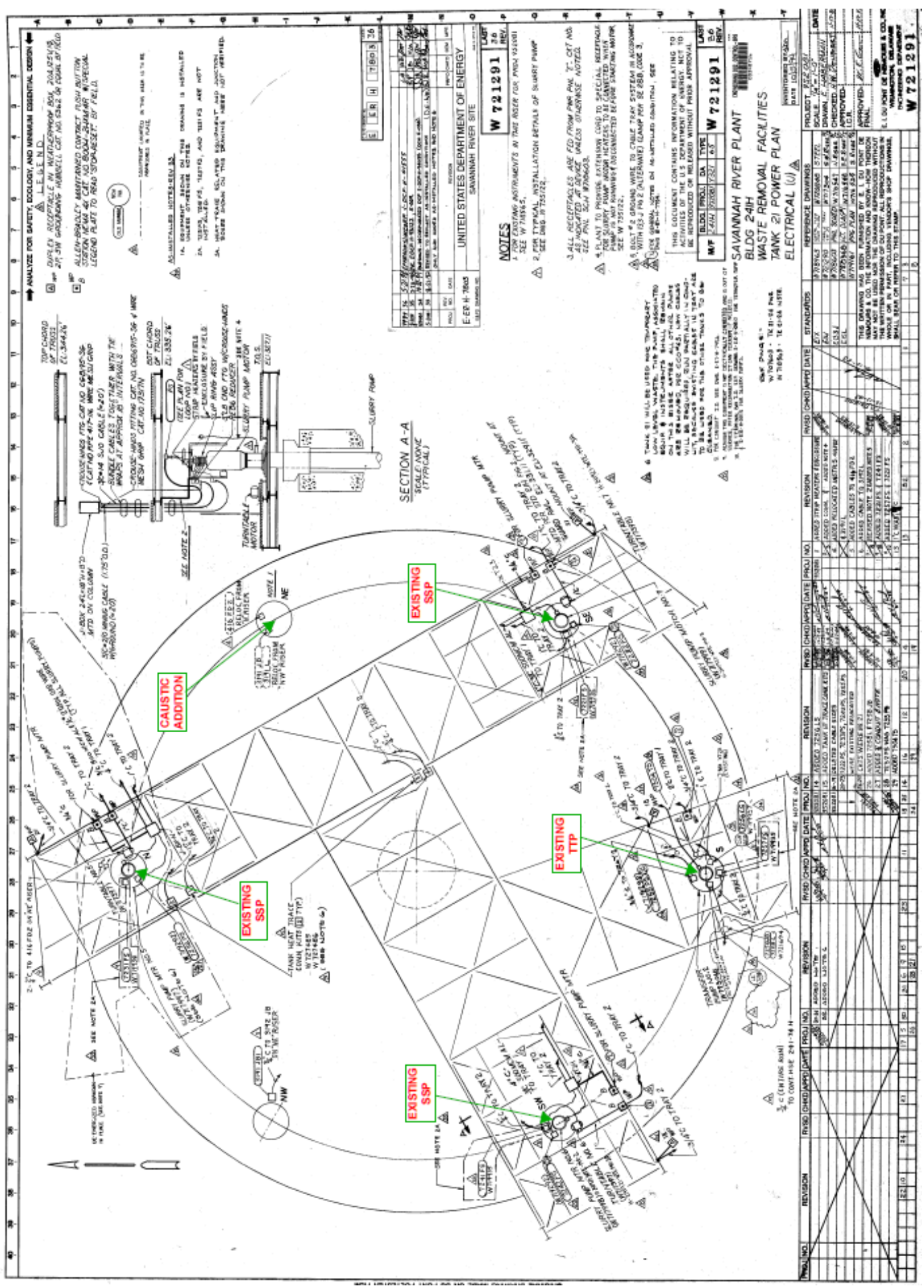

Figure 1. Tank 21 Pump Installations 


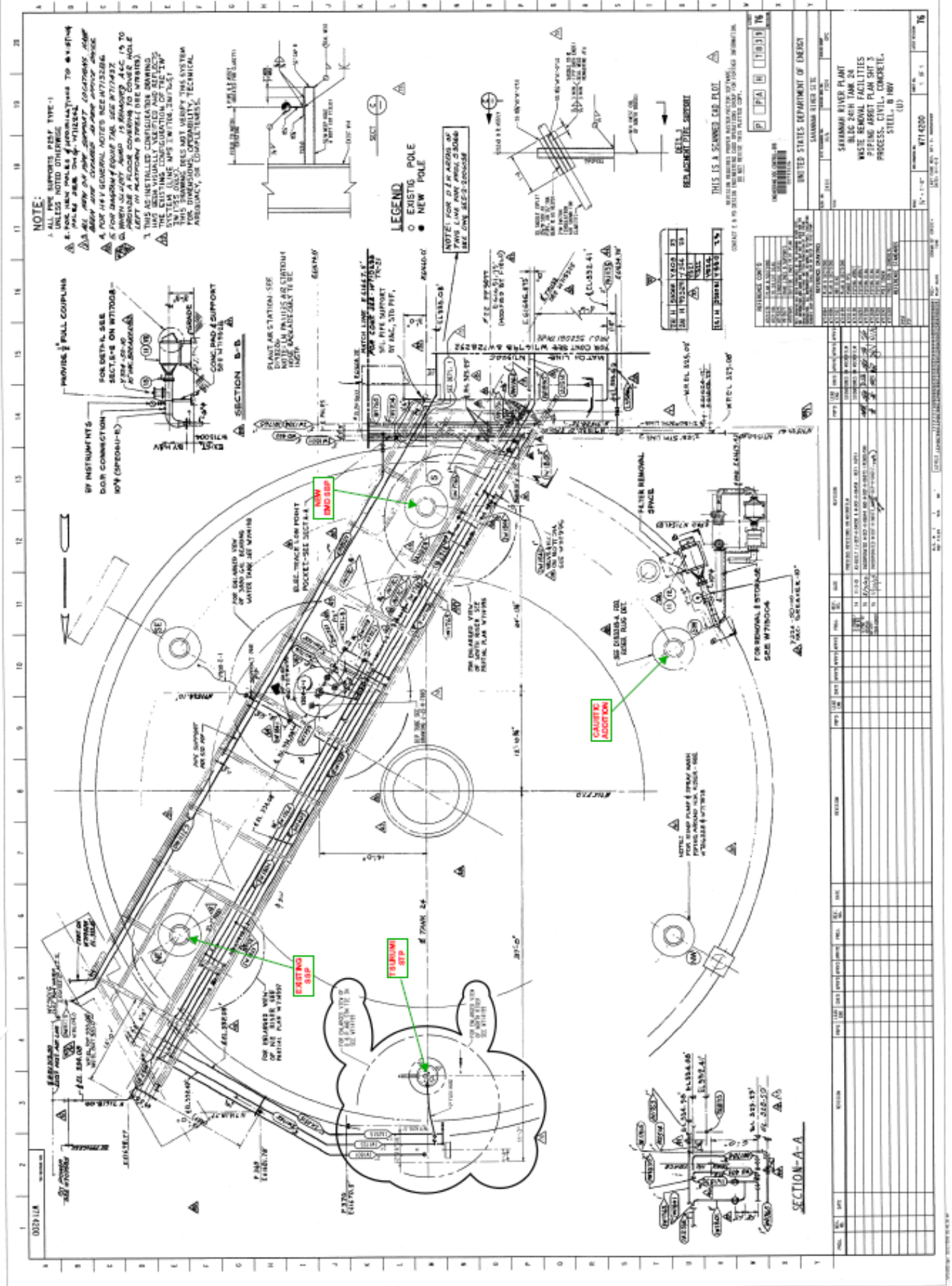

Figure 2: Tank 24 Pump Installations 


\subsection{CFD MODEL REQUIREMENTS}

The salt feed must be a reasonably homogeneous solution, and must also satisfy the acceptance criterion of the solids entrainment during transfer operations. To consider this blending process, CFD modeling consisted of two principal objectives to evaluate the requirements for blending of Tank 21 and transfer pumps for Tank 21 and Tank 24. Tank 24 blending was evaluated, using engineering judgment and Phase 2 test results. One objective was to estimate the $95 \%$ blending time of the tank solutions using the existing Standard Slurry Pump for blending operations in Tank 21, before transferring the solutions to the SWPF feed tank. The $95 \%$ blending time is defined as the time for a continuous liquid phase to reach a spatially uniform composition of the discontinuous blending species over the entire liquid domain of the tank within $95 \%$ homogeneity when the tank initially contains zero species concentration. The other objective was to evaluate the effectiveness of using an existing Tank 21 Hazelton transfer pump and a planned Tank 24 Tsurumi transfer pump for transferring solutions from the tanks. During transfer operations of the blended tank contents to the SWPF, solids entrainment of the sludge particles from the tank floor must be controlled to less than $1200 \mathrm{mg} / \mathrm{liter}$. Pertinent dimensional details of the pumps are summarized in this report, and additional dimensional details and equipment descriptions are available in the TTQAP (Leishear, Fowley [7]), TTR (Ervin [8]), and Phase 1 and 2 reports (Leishear, Fowley, and Poirier [1, 2]).

\subsection{BLENDING PUMP MODELS}

Following the basic solution methodology developed and validated in the previous work (Lee, et al. $[9,10])$, the CFD approach was applied by using a full scale, three-dimensional configuration of an SRS Type-IV tank (Tank 21). Shown in Figure 3, the tank wall boundary and major solid obstructions such as a transfer pump column, and three slurry pump housings (including one active and two inactive pumps) were included in the blending performance model. Modeled slurry pump dimensions are also shown in Figure 3. The work scope described here consists of two modeling areas. They are the transient mixing analysis during miscible liquid blending operation, and the steady state flow pattern analysis during transfers of the blended liquid from the tanks.

\subsubsection{Blending Pump Installation and Operation}

In Tank 21, three slurry mixing pumps are installed into the waste tanks through 0.57-m diameter riser openings and mounted to rotating turntables located on the tank roofs. Dimensions and operating parameters for the present blending pump design are summarized in Table 1. The blender pump located at the Southwest riser is planned to be used for solution blending in Tank 21, and this location was used for CFD modeling. The blender pump design employs a bottom suction inlet and two horizontal, opposing discharge nozzles, where the tank solution is drawn up through the suction and is discharged through the two jet nozzles to blend the tank contents. The pump is immersed in 345 inches of solution at 68.75 inches above the tank floor. The nozzle diameters are 1.5 inches, and the nozzle discharge design velocities equal $109 \mathrm{ft} / \mathrm{sec}$. Consequently, the jet discharges fullydeveloped turbulent flow under typical operating conditions, since the Reynolds number is approximately $10^{6}$ in terms of the jet diameter and discharge velocity. Jet flows from the nozzles not only blend the tank contents, but may disturb and lift sedimented waste, or sludge, from the tank bottom. 
Table 1. Pump design and modeling parameters for slurry pump used for jet blending operations at SRS

\begin{tabular}{|c|c|c|}
\hline \multicolumn{2}{|c|}{ Pumps } & Standard slurry pump \\
\hline \multicolumn{2}{|c|}{ Tank diameter, $\mathrm{ft}$} & 85 \\
\hline \multicolumn{2}{|c|}{ Tank liquid level, inches } & 345 \\
\hline \multicolumn{2}{|c|}{ Power, hp } & 300 \\
\hline \multicolumn{2}{|c|}{ Number of nozzles } & 2 \\
\hline \multicolumn{2}{|c|}{ Flow rate per nozzle*, gpm } & 600 \\
\hline \multicolumn{2}{|c|}{ Number of pumps } & 1 \\
\hline \multicolumn{2}{|c|}{$\begin{array}{l}\text { Nozzle diameter of standard slurry pump, } \\
\text { inches }\end{array}$} & 1.5 \\
\hline \multicolumn{2}{|c|}{ Pump rotation (for the present analysis) } & No (Indexed pump) \\
\hline \multirow{2}{*}{$\begin{array}{l}\text { Tank fluid } \\
\text { properties } \\
\left(\text { Nitrate }^{\star *}\right)\end{array}$} & Density, gm/ml & 1.32 \\
\hline & Viscosity, cp & 2.26 \\
\hline \multicolumn{2}{|c|}{$\begin{array}{l}\text { Pump nozzle elevation above tank } \\
\text { bottom, inches }\end{array}$} & 68.75 \\
\hline \multicolumn{2}{|c|}{$\begin{array}{l}\text { Velocity at nozzle exit } \\
\mathrm{ft} / \mathrm{sec}(\mathrm{m} / \mathrm{sec})\end{array}$} & $\begin{array}{l}108.9 \\
(33.2)\end{array}$ \\
\hline \multicolumn{2}{|c|}{$\mathrm{U}_{0} \mathrm{~d}_{0}^{*}, \mathrm{ft}^{2} \sec ^{-1}\left(\mathrm{~m}^{2} \sec ^{-1}\right)$} & $13.6(1.265)$ \\
\hline
\end{tabular}

Note: *The baseline parameters were based on the nominal conditions for blending of tank contents (U-TTR-H-00019 [Ref. 8]), acid $\left(\mathrm{HNO}_{3}\right)$.

** Tank fluid was assumed to be blended using tracer quantities of acid $\left(\mathrm{HNO}_{3}\right)$ of $1.142 \mathrm{gm} / \mathrm{ml}$ density and $1.160 \mathrm{cp}$ viscosity for the blending calculations.

\subsubsection{Previous Research}

Although there is considerable technical literature on mixing and solid suspension in agitated tanks, very little literature has been published on jet mixing in large-scale tanks [Refs. 9, 13]. Additionally, basic flow pattern behaviors were benchmarked against the Phase 1 and 2 test results, with and without installed cooling coils, in the previous work [Ref. 9]. The transient blending time calculations were performed for the addition of tracer solutions by using the $95 \%$ homogeneity criterion for the entire liquid domain of the tank, which means that the blended liquid in every computational cell has reached at least $95 \%$ of the fully mixed species concentration. The initial conditions for the entire modeling domain were based on steady-state flow patterns with zero initial second phase concentrations. Those previous modeling calculations and analyses for liquid blending [Refs. 9, 10] were performed for several different pump configurations, using a combination of pump types and 
tank wall boundaries. For those configurations, evaluations were performed for the resulting flow patterns, and the impact of the flow pattern on particle entrainment from the sludge layer.

During the blending operation, the solids layer settled on the tank floor will be disturbed and suspended by the jets of discharged liquid into the bulk liquid. Prior to transferring the blended tank contents to the SWPF feed tank, adequate settling time (paragraph 6.0) and enough separation distance of the transfer pump suction to the solids layer (paragraph 3.2) are required to satisfy the SWPF waste acceptance criteria, which requires minimal solids entrainment via the Tank 21 and Tank 24 transfer pumps.

\subsubsection{Present Blending Research}

Blending time calculations were performed using a two-step approach for tracer quantities of solution in the Tank 21 bulk contents. The first step was to establish the steady-state turbulent flow patterns created by a submersible blender pump, using pertinent species balance equations. The second step was to perform the transient modeling calculations by starting with another set of species balance equations, coupled with the established steady state, turbulent flow patterns. Although both the blending pump model and the transfer pump flow models were benchmarked and validated against the test results from the previous 1/10.85 scale model experiments [Refs. 9, 10], additional benchmarking of the blending model against the literature data was performed here for further blending model validation. This additional work showed that this additional CFD model agreed with the average blending time predicted by Grenville and Tilton (Ref. 14) to within about 3\%, even though Grenville's data varied by significantly more for other examples.

In addition to benchmarking single nozzle operations, dual nozzle pumps were investigated. Overall, CFD calculation results showed that a dual nozzle pump with flow rates of $600 \mathrm{gpm}$ per nozzle blends the 1.2 million gallon volume contained in Tank 21 in about 38 minutes to yield $95 \%$ homogeneity of the tank contents. This initial estimate requires correction for experimental variations determined during Phase 1 and Phase 2 testing. Also, this estimated blending time may significantly increase when bulk addition effects are considered for adding lighter to heavier fluids.

\subsection{TRANSFER PUMP MODELS}

Transfer pump calculations were performed to describe flow patterns and to evaluate the effectiveness of an existing Tank 21 Hazelton transfer pump and a planned Tank 24 Tsurumi transfer pump for use in SDI transfers. Modeled pump elevations were selected based on planned operating conditions. Table 2 provides pump dimensions and operating parameters. Other pump elevations were not investigated. Transfer pump dimensions were provided by SRR Engineering.

\subsubsection{Acceptance Criteria}

To evaluate transfer pump performance during transfers of blended contents to the SWPF, solids entrainment of the sludge layer settled on the tank floor must be kept below an acceptable solids concentration. To meet this requirement, a maximum fluid velocity of $0.022 \mathrm{ft} / \mathrm{sec}$ at the sludge surface is required to prevent any sludge entrainment during a transfer, as established in the previous testing and analysis [Refs. 9, 10] using a low yield stress sludge simulant to ensure conservative results. Establishing this characteristic velocity for SRS sludge allows the local fluid velocity at the sludge surface due to transfer 
pump operation to be employed as a criterion for no sludge entrainment during the transfer of blended tank contents. The flow patterns and velocity distributions near the suction inlet at the sludge surface of the transfer pump were compared to this velocity criterion. Only one sludge depth was modeled for each tank, as listed in Table 2. Suction screens are neglected in the CFD models.

\subsubsection{Tank 21 Transfer Pump Summary}

In Tank 21, the existing Hazelton transfer pump has no solid plate installed below the pump suction screen, as shown in Figure 4. For a Hazelton transfer pump, calculation results showed that when the pump is placed 52.9 inches above the sludge layer, the maximum local velocity on the top surface of sludge layer equals $0.0013 \mathrm{ft} / \mathrm{sec}$. These results demonstrate that maximum velocities at the top surfaces of the sludge layers settled in Tank 21 satisfies the acceptance criterion of no sludge entrainment, where a velocity of 0.022 $\mathrm{ft} / \mathrm{sec}$ was established in the Phase 2 research.

\subsubsection{Tank 24 Transfer Pump Summary}

In Tank 24, a Tsurumi pump is planned to have a 10.5 in solid plate attached at the bottom of 3.5 inch high suction screen, as shown in Figure 5. For a Tsurumi pump, the maximum sludge surface velocity is $0.013 \mathrm{ft} / \mathrm{sec}$ for transfer operations. These results demonstrate that maximum velocities at the top surfaces of the sludge layers settled in Tank 24 satisfies the acceptance criterion of no sludge entrainment, where a velocity of $0.022 \mathrm{ft} / \mathrm{sec}$ was established in the Phase 2 research. 


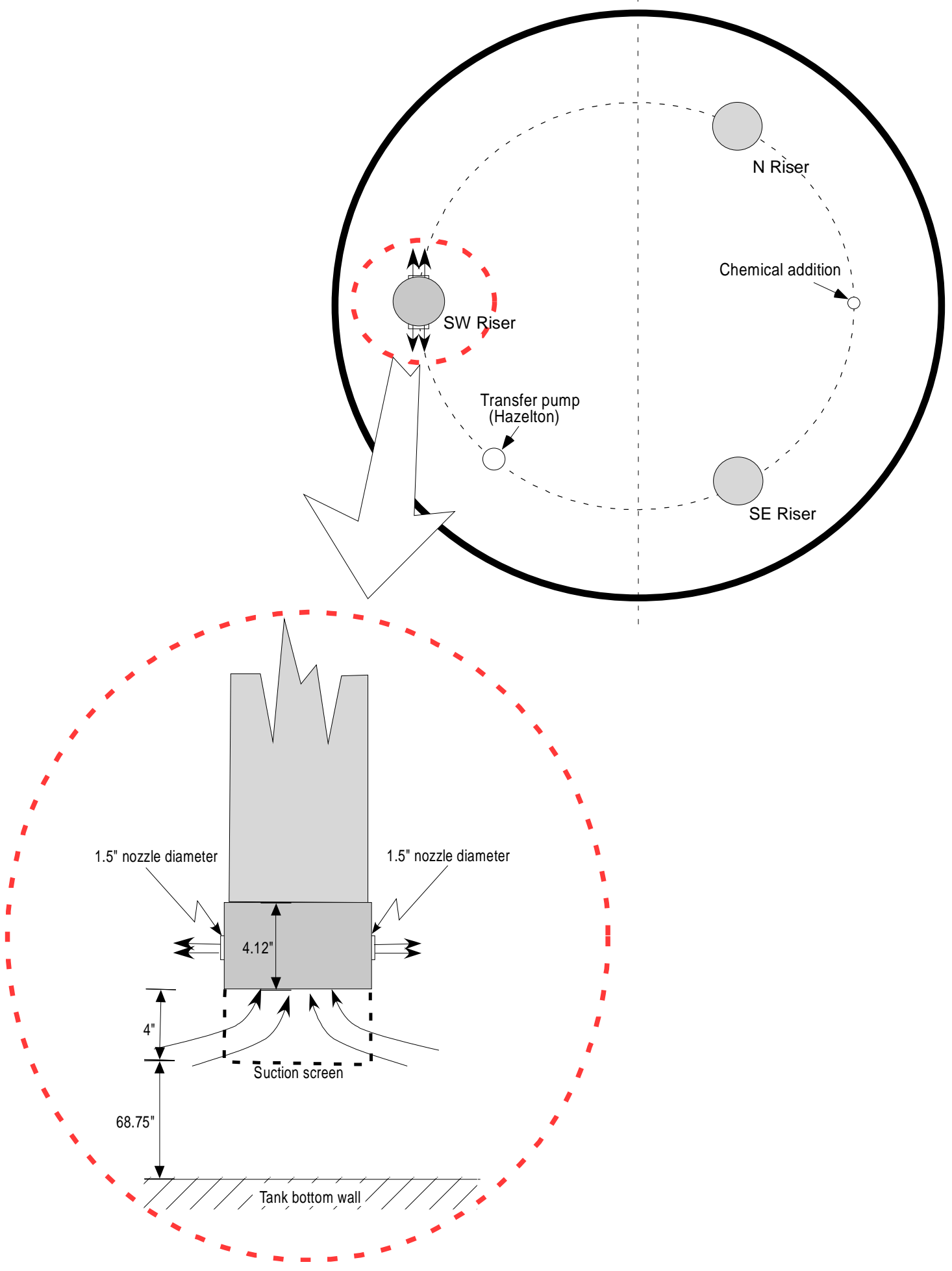

Figure 3. Modeling geometry used for the Tank 21 blending time calculations of the standard slurry pump with dual jets 
Table 2. Pump design and modeling parameters for Tank 21 and Tank 24 transfer pump operations

\begin{tabular}{|c|c|c|}
\hline \multicolumn{2}{|c|}{ Pumps } & Transfer pump \\
\hline \multicolumn{2}{|c|}{ Tank diameter, ft } & 85 \\
\hline \multicolumn{2}{|c|}{ Tank liquid level, inches } & 345 \\
\hline \multicolumn{2}{|c|}{$\begin{array}{l}\text { Flow rate for Hazelton pump } \\
\qquad \text { (Tank 21), gpm }\end{array}$} & 100 \\
\hline \multicolumn{2}{|c|}{$\begin{array}{l}\text { Flow rate for Tsurumi pump } \\
\text { (Tank 24), gpm }\end{array}$} & 100 \\
\hline \multicolumn{2}{|c|}{ Number of pumps } & 1 \\
\hline \multicolumn{2}{|c|}{$\begin{array}{c}\text { Inlet diameter for Hazelton, } \\
\text { inches }\end{array}$} & 3.0 \\
\hline \multicolumn{2}{|c|}{$\begin{array}{l}\text { Inlet diameter for Tsurumi, } \\
\text { inches }\end{array}$} & 3.11 \\
\hline \multirow{2}{*}{$\begin{array}{l}\text { Pump nozzle } \\
\text { elevation } \\
\text { above sludge } \\
\text { layer, inches }\end{array}$} & $\begin{array}{l}\text { Hazelton pump } \\
\quad \text { (Tank 21) }\end{array}$ & $\begin{array}{c}52.9 \\
\text { (No plate on the bottom of the pump) }\end{array}$ \\
\hline & $\begin{array}{l}\text { Tsurumi pump } \\
\text { (Tank 24) }\end{array}$ & $\begin{array}{c}12.5 \\
\text { (Solid plate located } 9 \text { inches above sludge } \\
\text { layer) }\end{array}$ \\
\hline \multirow[t]{2}{*}{$\begin{array}{l}\text { Sludge level, } \\
\text { inches }\end{array}$} & $\begin{array}{l}\text { Hazelton pump } \\
\quad(\text { Tank 21) }\end{array}$ & 15.1 \\
\hline & $\begin{array}{l}\text { Tsurumi pump } \\
\text { (Tank 24) }\end{array}$ & 1 \\
\hline \multicolumn{2}{|c|}{$\begin{array}{l}\text { Velocity at Tank } 21 \text { pump inlet, } \\
\mathrm{ft} / \mathrm{sec}(\mathrm{m} / \mathrm{sec})\end{array}$} & $\begin{array}{c}4.54 \\
(1.38)\end{array}$ \\
\hline \multicolumn{2}{|c|}{$\begin{array}{l}\text { Velocity at Tank } 24 \text { pump inlet, } \\
\mathrm{ft} / \mathrm{sec}(\mathrm{m} / \mathrm{sec})\end{array}$} & $\begin{array}{c}4.22 \\
(1.29)\end{array}$ \\
\hline
\end{tabular}




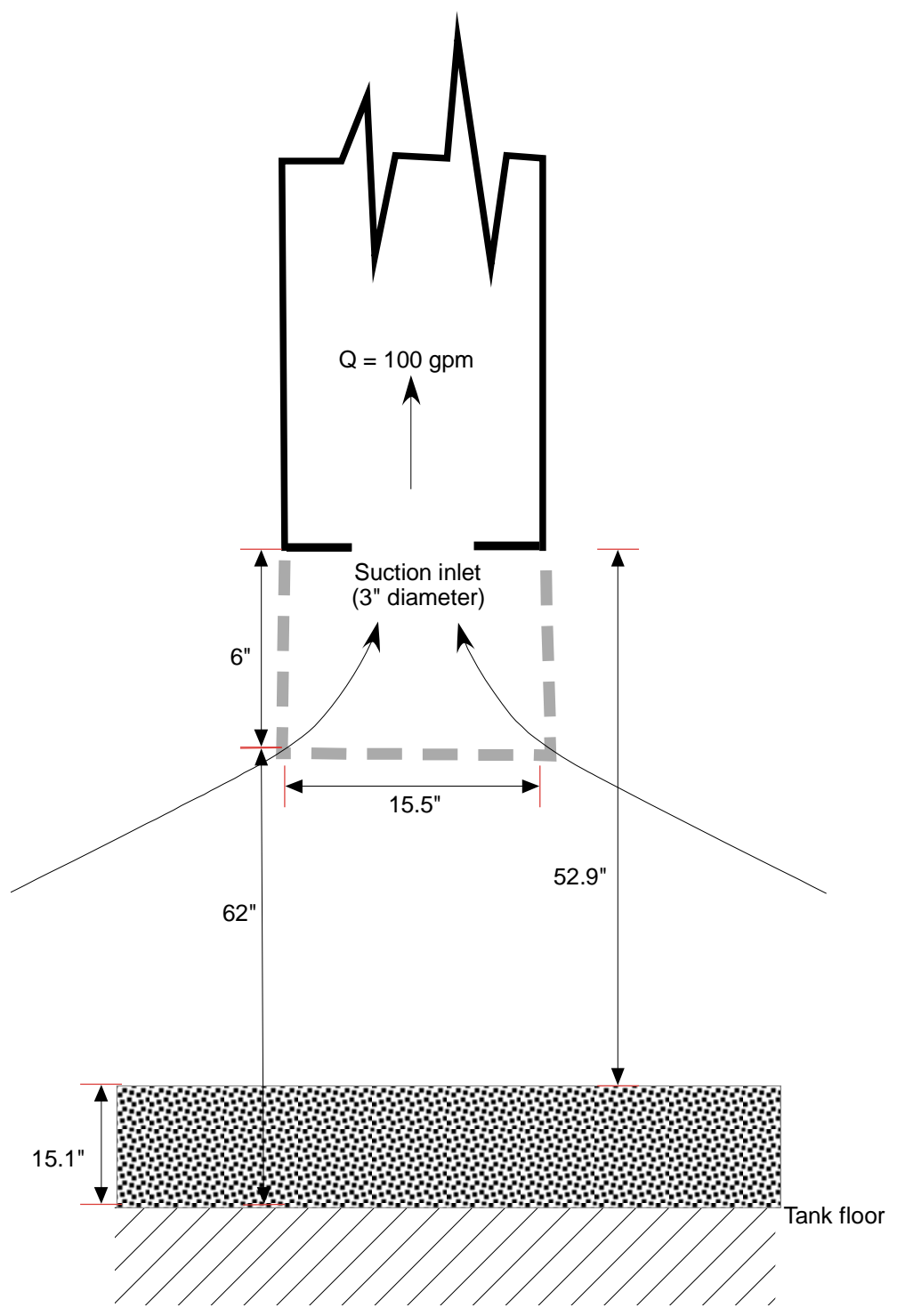

Figure 4. Hazelton transfer pump model configuration in Tank 21 


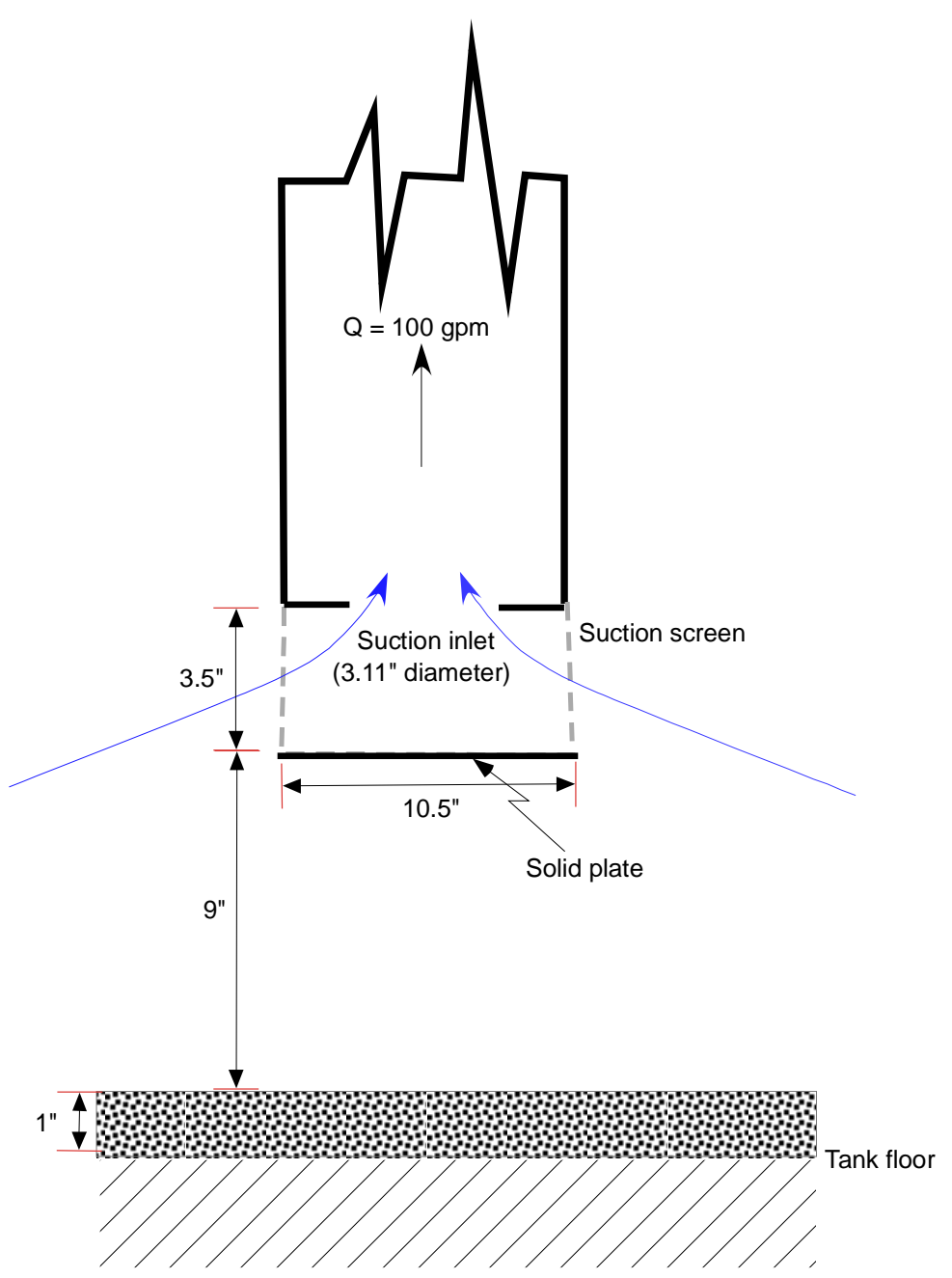

Figure 5. Tsurumi transfer pump model configuration in Tank 24

\subsection{CFD SOLUTION METHODOLOGY}

This work consisted of two main objectives to investigate transfer and blending pumps. One objective was to estimate the blending time of the tank solutions when the existing Slurry Pump is used for the blending Tank 21 contents before transferring the solutions to the SWPF feed tank. The other objective was to evaluate the effectiveness of an existing Tank 21 Hazelton transfer pump and a planned Tank 24 Tsurumi transfer pump for use in SDI transfer service, so that the solids entrainment from the sludge layer settled on the tank floor meets minimum acceptance criteria. A three-dimensional CFD approach was taken to achieve these objectives.

\subsection{BLENDING TIME CFD MODEL}

All the present calculations were performed by the CFD modeling techniques validated by the previous reports for blending of tracers in bulk fluid volumes [Refs. 9, 10]. The commercial finite volume code, FLUENT, was used to create a full scale geometry file in a non-orthogonal mesh environment. The model geometry was created using the body-fitted 
coordinate system and structured multi-block grids. For the blending performance analysis, the reference modeling conditions were considered as shown in Figure 3 and Table 1 . The blending pump is submerged inside a cylindrical tank that is 345 inches high and 85 feet in diameter. The nozzle diameters equaled 1.5 inches, and the dual opposing nozzles were directed parallel to the tank wall as shown Figure 3. The computational domain for the modeling calculations is presented in Figure 6, and the computational meshes corresponding to the modeling domain of Figure 6 are shown in Figure 7. From the mesh sensitivity analysis, about $4.2 \times 10^{6}$ mesh nodes were established for the Tank 21 blending calculations as depicted in the figure.

\subsubsection{Governing Equations}

For the modeling calculations, the transient governing equations consisted of one mass balance, three momentum equations, two turbulence transport equations for kinetic energy $(k)$ and dissipation rate $(\varepsilon)$, and one species transport equation. These equations were solved by an iterative technique until the species concentrations of tank fluid were within 5\% relative error from the equilibrium concentration, which represented the $95 \%$ blending criterion. The relative error $\varepsilon_{m}$ was estimated by Eq. (1). The steady-state flow solutions for the entire tank fluid were used for the initial conditions of the transient species calculations.

$\varepsilon_{m}=\left|\frac{C-C_{e q}}{C}\right|<0.05$

The parameters in Eq. (1), $C_{e q}$ and $C$, are equilibrium and transient concentrations at a monitoring point, respectively.

In the present analysis, the upper liquid surface in the tank was assumed to be frictionless for computational efficiency, neglecting the detailed wave motion of the free surface. That behavior does not have a significant impact on the flow patterns inside the blending region, since there is a large separation distance of about 276 inches between the top liquid surface and the discharge nozzle in this 345 inch deep tank. The fluid properties of salt solution were applied at constant temperature $\left(20^{\circ} \mathrm{C}\right)$, as listed in Table 1 . The flow conditions for the pump operations were assumed to be fully turbulent since Reynolds numbers for typical operating conditions are in the range of $7 \times 10^{5}$ to $1.0 \times 10^{6}$, based on the pump nozzle inlet conditions. A standard two-equation turbulence model, the $\kappa-\varepsilon$ model [12] was used to capture the turbulent flow evolution driven by the dual jets of the blending pumps. To further demonstrate the applicability of the turbulence model, previous work (Lee et al., [12]) showed that the two-equation model predicted the flow evolution of turbulent jets in a large stagnant fluid domain with reasonable accuracy. This model specifies the turbulent or "eddy" viscosity $v_{t}$ by the empirical equation.

$v_{t}=\frac{\mu_{t}}{\rho_{f}}=\left(\frac{C_{\mu} k^{2}}{\varepsilon}\right)$

In Eq. (2), $C_{\mu}$ is an empirical constant. In the present calculations, $C_{\mu}$ equals 0.09 . Thus, the turbulent energy dissipated by the blending operation is computed by solving two transport equations for $k$ (turbulent kinetic energy), and $\varepsilon$ (rate of dissipation of turbulent energy). 
From these two key parameters of $k$ and $\varepsilon$, a length scale $\left(k^{1.5} / \varepsilon\right)$, a time scale $(k / \varepsilon)$, and a quantity of turbulent eddy diffusivity $\left(k^{2} / \varepsilon\right)$, can be formed (Jones and Launder [15]). Turbulent kinetic energy $(k)$ is the mean kinetic energy per unit mass associated with eddies in turbulent flow. Physically, the turbulent kinetic energy is characterized by measured rootmean-square (rms) velocity fluctuations. In the Reynolds-averaged Navier Stokes equations, the turbulent kinetic energy can be calculated based on the closure method, i.e. a turbulence model. Generally, the turbulent kinetic energy can be quantified by the mean of the turbulence normal stresses:

$k=\frac{1}{2}\left\{\overline{\left(u_{x}\right)^{2}}+\overline{\left(u_{y}\right)^{2}}+\overline{\left(u_{z}\right)^{2}}\right\}$

$k$ can be produced by fluid shear, friction or buoyancy, or through external forcing at lowfrequency eddie scales (integral scale). Turbulent kinetic energy is then transferred down the turbulence energy cascade, and is dissipated by viscous forces at the Kolmogorov molecular diffusion scale. This process of production, convective transport, and dissipation as modeled for a $k$ transport balance in the two-equation turbulence model can be expressed as:

$$
\frac{D k}{D t}=\nabla \cdot\left(\frac{v_{T}}{\sigma_{k}} \nabla k\right)+P-\varepsilon
$$

The three other terms, $-D k / D t, P$, and $\varepsilon$, are in closed form, given the turbulent-viscosity hypothesis.

Turbulence consists of high levels of fluctuating vorticity. At any instant, vortical motion called eddies are present in the flow. These eddies range in size from the largest geometrical scales of the flow; such as tank diameter, down to small eddies where molecular diffusion dominates. Eddies are continuously evolving, and the superposition of their induced motions leads to fluctuating waves. In this situation, turbulent kinetic energy is dissipated from the largest eddies down to the smallest through a process called energy cascade. In order to maintain turbulence, a constant supply of energy must be fed to the turbulent fluctuations at the largest scales from the mean motions, where motions are driven by a pump or mechanical agitator. Thus, the turbulent energy dissipation rate $\varepsilon$ is viewed as the energy-flow rate in the cascade, and the rate is determined by large-scale motions, which are independent of the viscosity at high Reynolds number. Consequently, the transport equation for $\varepsilon$ may be considered as being entirely empirical. That is,

$\frac{D \varepsilon}{D t}=\nabla \cdot\left(\frac{v_{t}}{\sigma_{\varepsilon}} \nabla \varepsilon\right)+C_{1}\left(\frac{\varepsilon}{k}\right) P-C_{2} \frac{\varepsilon^{2}}{k}$

Consequently, the governing equations to be solved for the present work are composed of one continuity equation and three momentum equations for the three component directions ( $x, y$, and $z$ directions), and two constitutive equations for the turbulence descriptions.

When a tracer species; such as acid material is added to the tank during blending operations before transferring the tank contents, the added species are transported over the tank domain by the continuous fluid motion driven by the pump. The modeling calculations for the blending time require a balance equation for tracer species. The species balance equation is given by 
$\frac{\partial \rho Y_{v}}{\partial t}+\nabla \cdot\left(\rho \vec{v} Y_{v}\right)=-\nabla \cdot \vec{J}_{v}+S_{v}$

$Y_{v}$ is a local mass fraction of tracer species in the continuous fluid. $\vec{J}_{v}$ is a diffusion flux of the tracer species. $S_{v}$ in the equation is a source term of tracer species added to the tank fluid due to the injection of the acid from the top of tank. The diffusion flux of the tracer under turbulent fluid flow is computed by

$\vec{J}_{v}=-\left(\rho D_{v}+\frac{\mu_{t}}{S c_{t}}\right) \nabla Y_{v}$

$D_{v}$ is a molecular diffusion coefficient of a tracer in the continuous fluid medium. Typical molecular diffusion coefficients of liquid species in the liquid domain are about $1 \times 10^{-9} \mathrm{~m}^{2} / \mathrm{s}$, which is much smaller than gas species.

The governing equations described above are solved over the entire tank domain of an SRS Type-IV tank without central support column and with no cooling coils, as shown in Figure 6. As shown in the figure, one inactive transfer pump and two slurry pumps were included in the modeling domain to consider the impact of the flow obstructions on the blending flow patterns. For the calculations, the domain was meshed by a hybrid meshing technique combined with hexahedral and tetrahedral meshes. The number of meshes for the domain with no cooling coils was established at about $4.2 \times 10^{6}$ nodes as shown in Figure 7.

\subsubsection{Tank 21 CFD Models}

A blending model for the Tank 21 configuration was set up with the horizontal discharges through the dual jets and flow return via pump suction, reflecting the full scale pump configuration shown in Figures 1 and 3. Based on the two-step approach for the pump configuration, the modeling calculations were made for the numerical simulation similar to those performed for the Phase 1 and 2 blending tests. The first step was to establish the steady-state flow patterns of submersible jet flows as performed for the experiments. The second step was to perform the transient modeling calculations starting with another set of species balance equation in addition to the continuity, momentum, and two turbulence equations.

In this approach, the transient calculations were started from the fully developed flow distribution of the first step steady-state runs as initial conditions. For the second step, a transient run was started with acid species injected into the fully-developed flow pattern established by the first step, and run until the acid species was mixed with the continuous phase in a homogeneous way within 95\%. Per SRR engineering, Tank 21 salt solution additions are done at the NE riser, and Tank 24 chemical additions are done at the SW riser. There is also an inhibited water addition downcomer in the $\mathrm{N}$ riser of Tank 24 . For the CFD models, contaminant species were added to the tank at the fully developed condition, where the species were then injected for 11.5 seconds through a 3 inch diameter hole at the top of the tank, which simulated a three inch diameter pipe. In this case, the species fluid was an acid of 1.14 specific gravity and $1.16 \mathrm{cp}$ viscosity. That is, the total volume injected through a modeled 3 inch diameter, Schedule 40 pipe was about 18 gallons during the initial period of 11.5 seconds, resulting in an equilibrium steady state mass concentration, $C_{e q}=$ $1.29 \times 10^{-5}$. The acid chemical species was injected at the Riser NE, as shown in Figures 1 
and 3. The transient local species profile at a monitoring point along with maximum and minimum concentrations in the tank were then calculated and observed. In short, the modeling calculations were performed to estimate the blending times for the Tank 21 jet flow conditions as defined in Table 1.

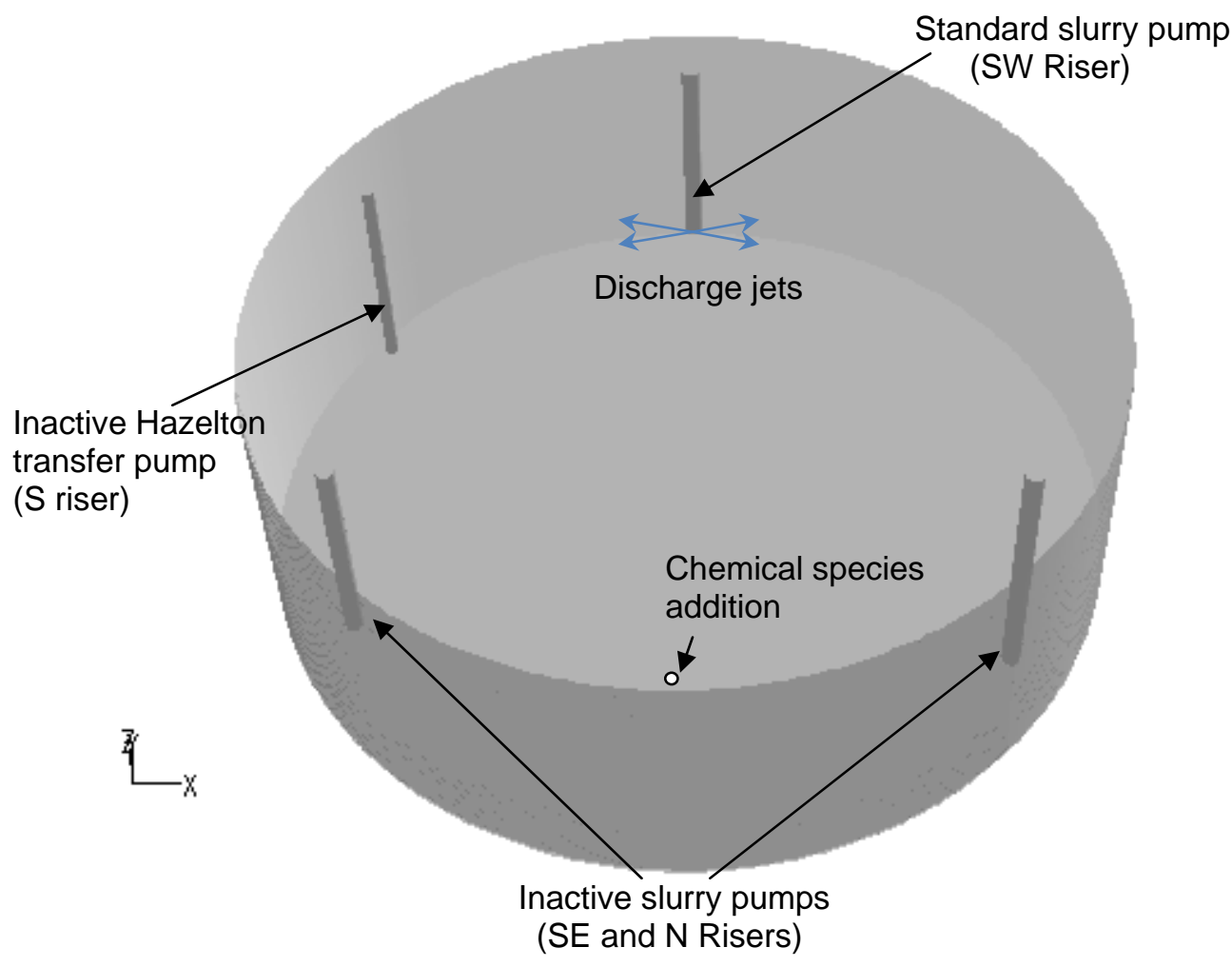

Figure 6. Three dimensional modeling domain used for the blending calculations 


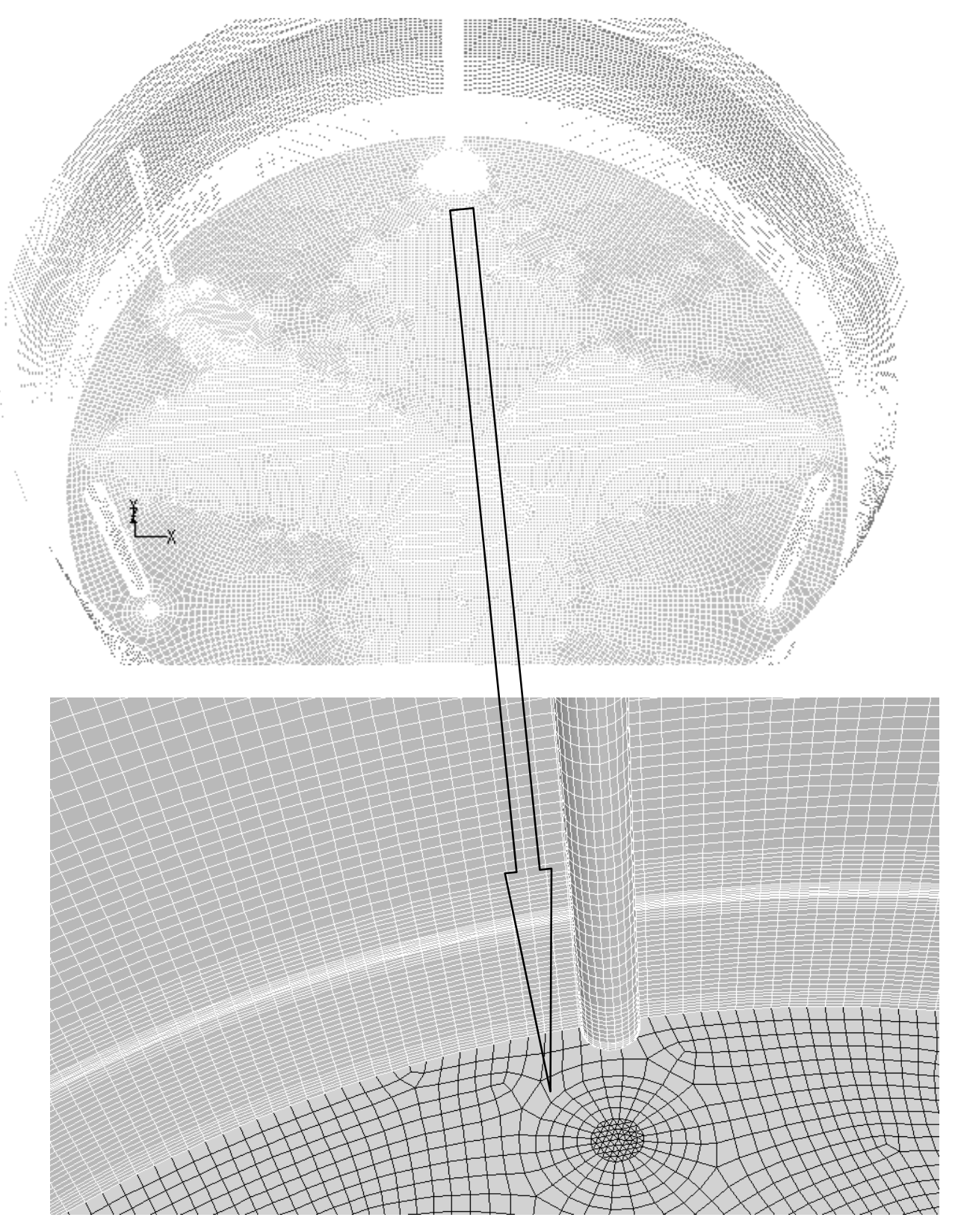

Figure 7. Computational domain and mesh nodes for the Tank 21 modeling domain $(4.2 \mathrm{x}$ $10^{6}$ meshes)

\subsection{TRANSFER PUMP CFD MODEL}

During transfers, homogeneous blending of salt solutions were required to be performed before the transfer of the blended solution to the SWPF, and only minor disturbances of settled sludge are permitted. The transfer pump model was developed to determine if the planned operational heights of the pumps are acceptable with respect to entrained solid concentrations during transfers to the SWPF. 
As shown in Figures 8 and 9, the computational domain does not include the sludge region, and the model assumes the top surface of the sludge layer to be frictionless. A frictionless model was shown to be acceptable in Phase 2 testing and modeling. As shown in the figures, the existing Hazelton transfer pump for Tank 21 has no solid plate, but the planned Tsurumi pump for Tank 24 has a solid plate 3.5 inches below the transfer pump suction inlet.

For the flow pattern calculations near the suction inlet of the transfer pump, the steady state governing equations consisting of one mass balance, three momentum equations, and two turbulence transport equations for kinetic energy $(k)$ and dissipation rate $(\varepsilon)$, which were solved by an iterative technique. The flow calculations were performed for the entire tank domain of an SRS Type-IV tank, such as Tank 21 and Tank 24. The computational domains are shown in Figures 10 and 11. For the calculations, the domain was meshed by an unstructured meshing technique with hexahedral meshes. The number of meshes for the Tank 21 domain with one Hazelton transfer pump was established as about $3.0 \times 10^{6}$ nodes for the mesh shown in Figure 10. The Tank 24 domain with Tsurumi pump was meshed as $4.0 \times 10^{6}$ nodes for the mesh shown in Figure 11 . 


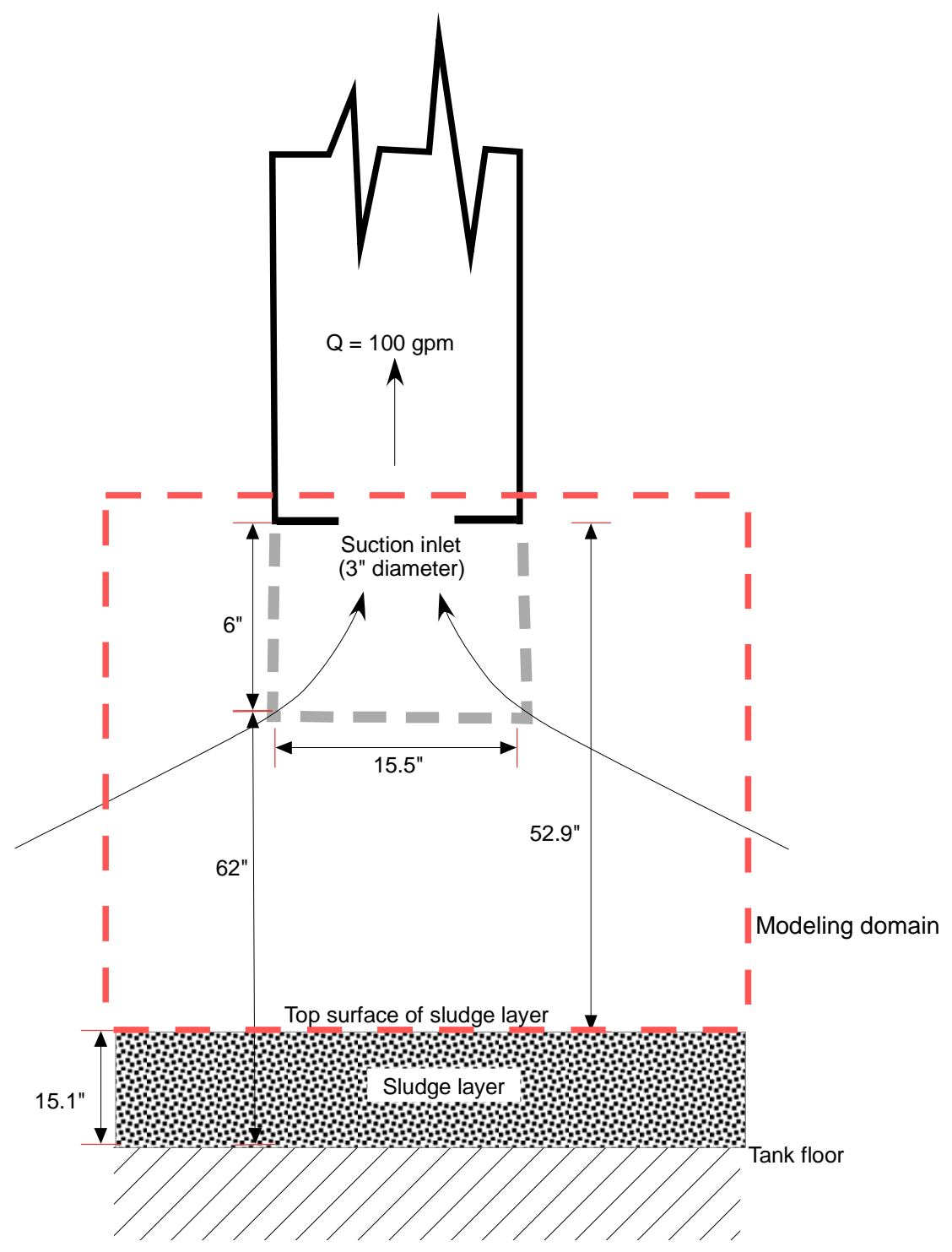

Figure 8. Computational domain for the Hazelton transfer pump model in Tank 21 


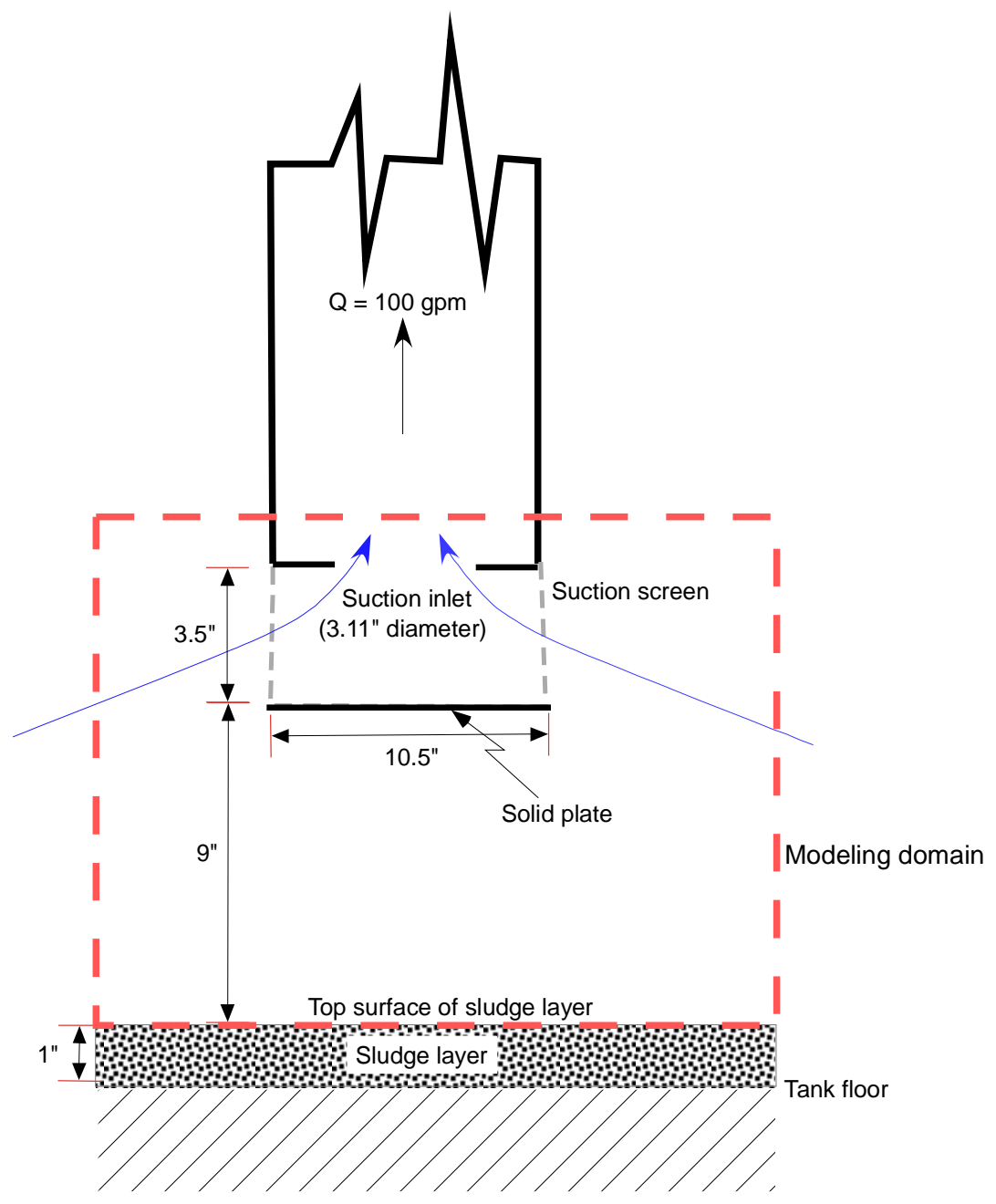

Figure 9. Computational domain for the Tsurumi transfer pump model in Tank 24 


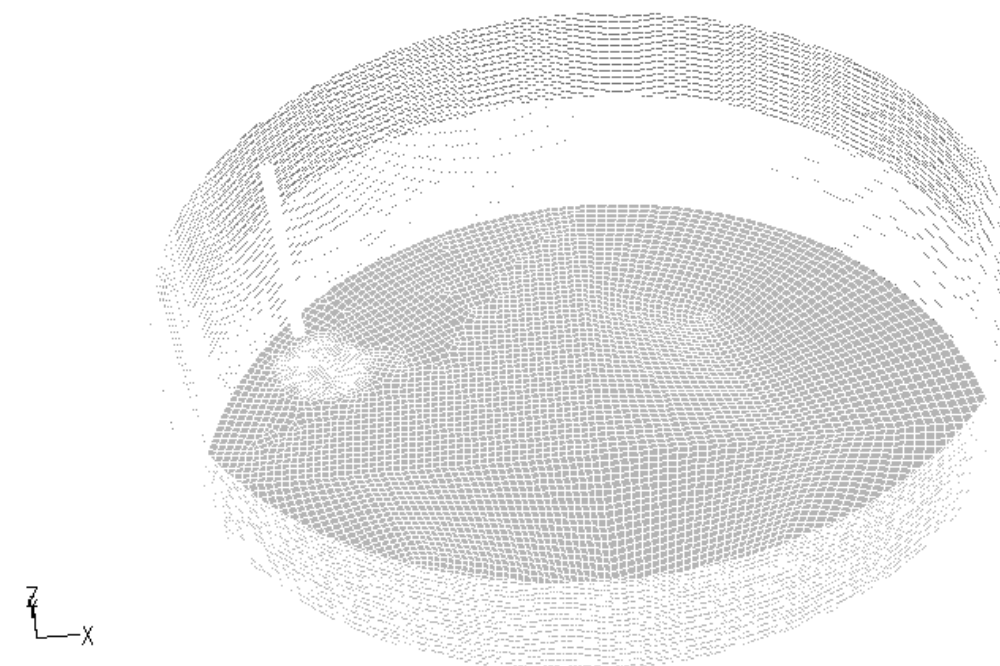

Figure 10. Computational domain and mesh nodes for the Tank 21 Hazelton transfer pump modeling domain $\left(3.2 \times 10^{6}\right.$ meshes $)$

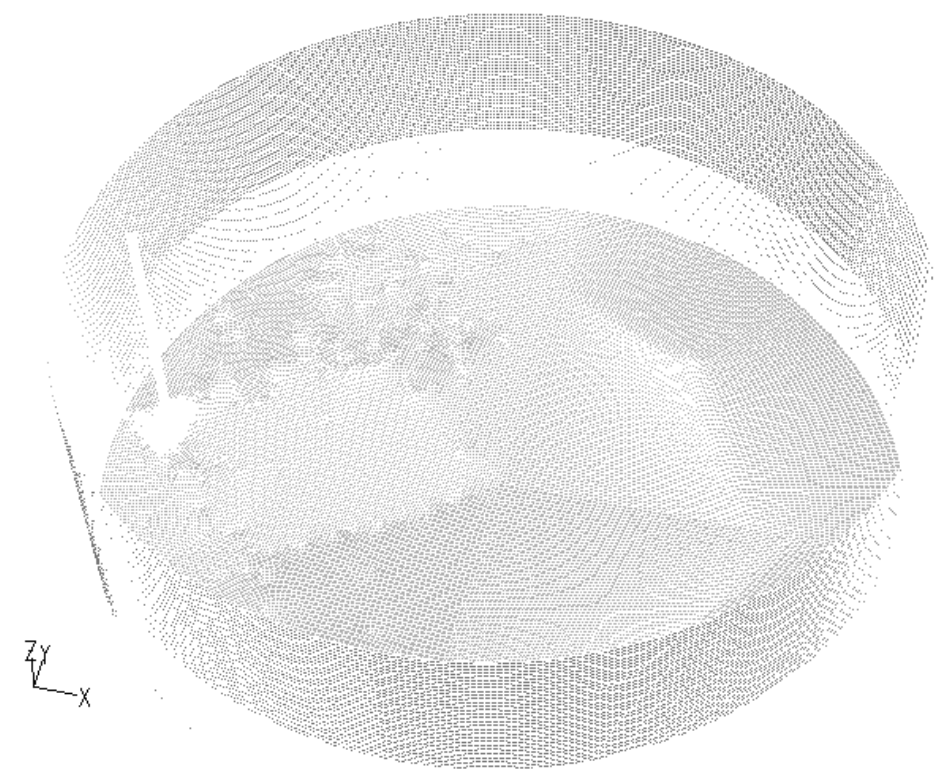

Figure 11. Computational domain and mesh nodes for the Tank 24 Tsurumi transfer pump modeling domain $\left(4.0 \times 10^{6}\right.$ meshes $)$ 


\subsection{CFD CALCULATION RESULTS AND DISCUSSIONS}

Based on the two-step approach, the modeling calculations were made for the numerical simulation as performed for the previous SDI project [Refs. 9, 10]. The first step was to establish the steady-state flow patterns of submerged jet flows. The second step was to perform the transient modeling calculations starting with another set of species balance equation in addition to the established turbulent flow patterns. In this approach, the transient calculations were started from the fully developed flow distribution of the first step steadystate runs as initial conditions. For the second step, a transient run was started with an acid species injected into the fully-developed flow pattern established by the first step, and run until the acid species was mixed with continuous phase to meet homogeneity requirements of $95 \%$ blending. Although the two-step model to estimate the blending time was benchmarked against the 1/10.85 scale experimental results conducted in Phase 1 and 2 research [Ref. 10], additional benchmarking of the blending model against literature results [Ref. 14] was also performed for the present work.

\subsection{CFD BENCHMARKING RESULTS}

The CFD blending time models were benchmarked against both pilot scale test data and literature data [Refs. 9, 10]. Comparisons to Grenville and Tilton's research from the literature [14], as well as CFD comparisons to Phase 1 and 2 research were performed.

\subsubsection{Literature Benchmarking Results for Blending}

A new model of the Tank A configuration shown in Table 3 was set up with the return path reflecting the actual tank configuration as described by Grenville and Tilton [Ref. 14]. The model configuration is shown in Figure 12. As shown in the figure, a jet pump with $42.6^{\circ}$ upward angle is located at the tank bottom, and the jetted flow returns to the pump through the tank bottom. Based on this model, the present two-step method was applied to estimate the blending time for benchmarking of Grenville's experimental work. In this approach, the transient calculations were again started from the fully developed flow distribution of the first step runs as initial conditions. The second step simulated the mixing tests performed by Grenville and Tilton [Ref. 14]. Figure 13 shows the fully developed flow patterns established by the first step. The second step was a transient calculation for a contaminant species started from the fully developed condition of the first run in which the species was injected for 10 seconds into the inlet jet. In this case, the species fluid was an acid with a 1.14 specific gravity and a $1.16 \mathrm{cp}$ viscosity, where the total volume injected through a $10 \mathrm{~mm}$ hole was approximately 0.21 gallons for an initial period of 10 seconds. Detailed test configurations and the computational domain of the Tank A system are shown in Figure 12. The transient species profile was then calculated and observed. Figure 14 shows Lagrangian flow path lines from the jet inlet to the tank exit for fully developed flow circulation inside the tank during the blending period.

For comparison of the species blending time with flow evolution time, a transient run with no species addition was started from stagnant tank fluid conditions and run until fully developed steady state flow patterns were established. The results of Table 3 are consistent with the two-step results shown in Figure 15. Comparison of transient snapshots between species concentration and flow patterns at a vertical central plane crossing the pump nozzle exit is made in Figure 15, indicating that the tank blending time is shown to be about 33 seconds, which is in agreement with Grenville's measured results of 32 seconds to within about 3\%. In the figure, species concentration was non-dimensionalized in terms of equilibrium species 
concentration of $3.02 \times 10^{-4}$. The results show very clearly that the injected contaminant species follows the velocity profile and that the propagation of the contaminant species develops over the same time period as both the bulk flow and the eddy flow patterns. The benchmarking results for blending time are shown in Figure 16. These results demonstrated that the CFD models predicted the test results for a range of jet $U_{0} d_{0}$ operating conditions within about $20 \%$ [Ref. 9], but uncertainty calculations were not performed for the data.

\subsubsection{Phase 1 and 2 Benchmarking Results for Velocity}

Localized tank velocities predicted by CFD models were benchmarked against both 1/10.85 pilot scale experiments and full scale test experiments. The CFD modeling predictions were previously benchmarked against the test results [Ref. 9, 10] for local velocities along the principal jet of the blending pump, and for more remote local velocities near the sludge layer. In an 8 foot diameter pilot scale tank used for Phase 1 and 2 testing, various azimuthal locations and different elevations were chosen for measurements of local velocities under steady-state operating conditions. Also, velocity measurements were compared to experiment in an 85 foot diameter tank at different elevations and positions (Leishear and Stefanko [12]). Measurements from both tanks were used to benchmark the CFD velocity measurements. All CFD results for the local velocities were compared to the experimental results obtained during 1/10.85 pilot scale tests and the full scale tests, as shown in Figure 17. The benchmarking results show that the CFD modeling predictions are in reasonable agreement, and that the test results appear to lie within about $25 \%$ throughout the range of the 1/10.85 for pilot scale and full scale tanks [Ref. 9]. To be more concise, a velocity correction factor of 1.27 was established in Phase 2 research, based on a confidence level of $95 \%$ which is typically applied for SRNL research. This correction factor statistically concludes that multiplying any calculated maximum CFD velocity at the top surface of sludge layer by 1.27 will yield a best estimate velocity 95 times out of 100 .

For transfer pumps, the Phase 2 acceptance criterion of $0.022 \mathrm{ft} / \mathrm{sec}$ was determined from experimental data [2] and CFD modeling results [9], when this velocity correction factor was applied. This validated velocity was then applied in this work to CFD calculations of flow patterns near the transfer pump inlets of Hazelton and Tsurumi pumps during transfers.

\subsubsection{Phase 1 and 2 Benchmarking Results for Blending Times}

For blending times, Phase 2 research combined the velocity correction factor with a statistical variance in the blending times to obtain a blending time correction factor, which equaled 3.35 for a tank with cooling coils installed. Although the correction factor for a tank without coils may be somewhat less, it was not calculated as part of the Phase 2 research. Consequently, the recommended blending time is multiplied by 3.35 to obtain the minimum blending time with $95 \%$ confidence.

For Tank 21, the blending time for miscible fluids then equals 38 minutes $\times 3.35=2$ hours, 13 minutes. Blending times may significantly increase if the viscosities and densities of the blended solutions are significantly different, and the added fluid is lighter than the fluid in the tank.

For Tank 24, blending times for a Type IIIA tank evaluated in Phase 2 are considered to be bounding. The blending time for a Submersible Blender Pump was determined in the Phase 2 report for a blending pump operating at the mid-height of the tank with a 1,225,000 gallon tank level (348 inch level). For these conditions, the maximum predicted full scale blending times were recommended as follows for a tank design without cooling coils, a center roof 
support column, and similar fluids. At $U_{0} d_{0}=4.85$ feet $^{2} /$ second, the recommended blending time is 4.86 hours. At $U_{0} d_{0}=3.58$ feet $^{2} /$ second, the recommended blending time is 6.58 hours. In other words, blending times for Tank 24 will be less than the blending times predicted in Phase 2 research for a tank without coils, since the difference in tanks and modeling is the presence of a central support column in Phase 2, which hinders blending and increases blending times. Phase 2 testing also noted that blending times may be increased to as long as three days to one week, depending on the viscosity differences between the blended solutions when the added fluid is lighter than the fluid in the tank. The effects of viscosity and density on blending times were not thoroughly studied in Phase 2 research.

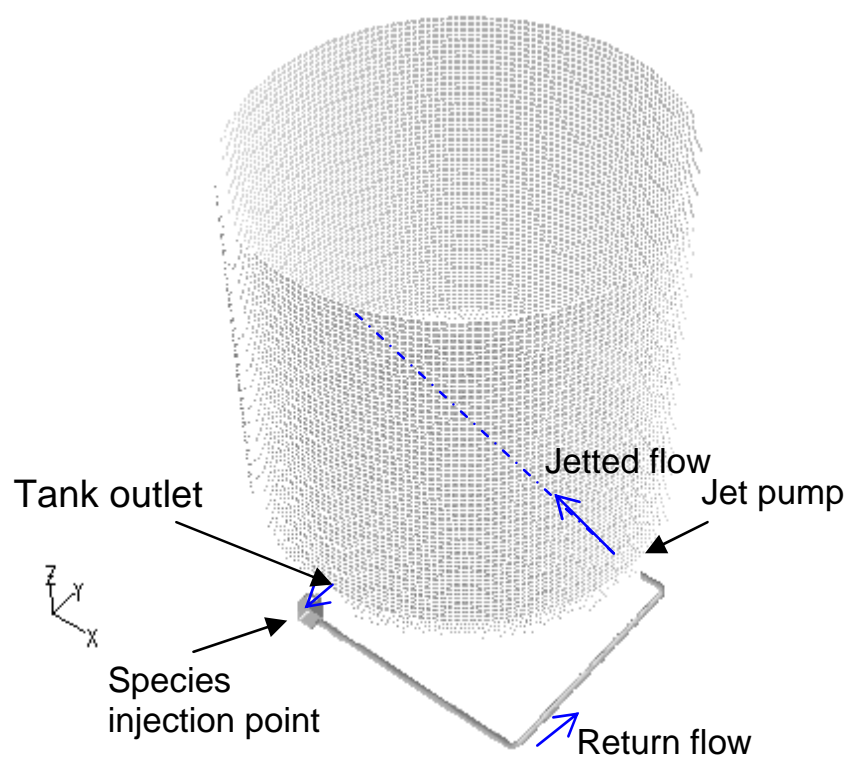

Figure 12 Tank A, geometry for the demonstration runs based on two different approaches of transient flow pattern and species transport calculations

Table 3. Test conditions and literature mixing times [Ref. 14] for transient CFD calculations

\begin{tabular}{|c|c|c|c|c|c|c|c|}
\hline Tank & $\begin{array}{c}D \\
\text { (Tank dia.) }\end{array}$ & $\begin{array}{c}h_{l} \\
\text { (liquid } \\
\text { height) }\end{array}$ & $\begin{array}{c}\text { Inclination } \\
\text { angle of Jet* }\end{array}$ & $\begin{array}{c}d_{o} \\
\text { (jet dia.) }\end{array}$ & $\begin{array}{c}U_{o} \\
\text { m/se } \\
\text { c }\end{array}$ & $R e_{j e t}$ & $\begin{array}{c}\text { Mixing time by } \\
\text { G-T correlation } \\
\text { [Ref. 14] }\end{array}$ \\
\hline Tank A & $1.68 \mathrm{~m}$ & $1.55 \mathrm{~m}$ & $42.6^{\circ}$ & $\begin{array}{c}26.1 \\
\mathrm{~mm}\end{array}$ & 19.8 & 516,780 & $32 \mathrm{sec}$. \\
\hline
\end{tabular}

Note: * Jet is located at the corner of tank bottom as shown in Figure 12. 

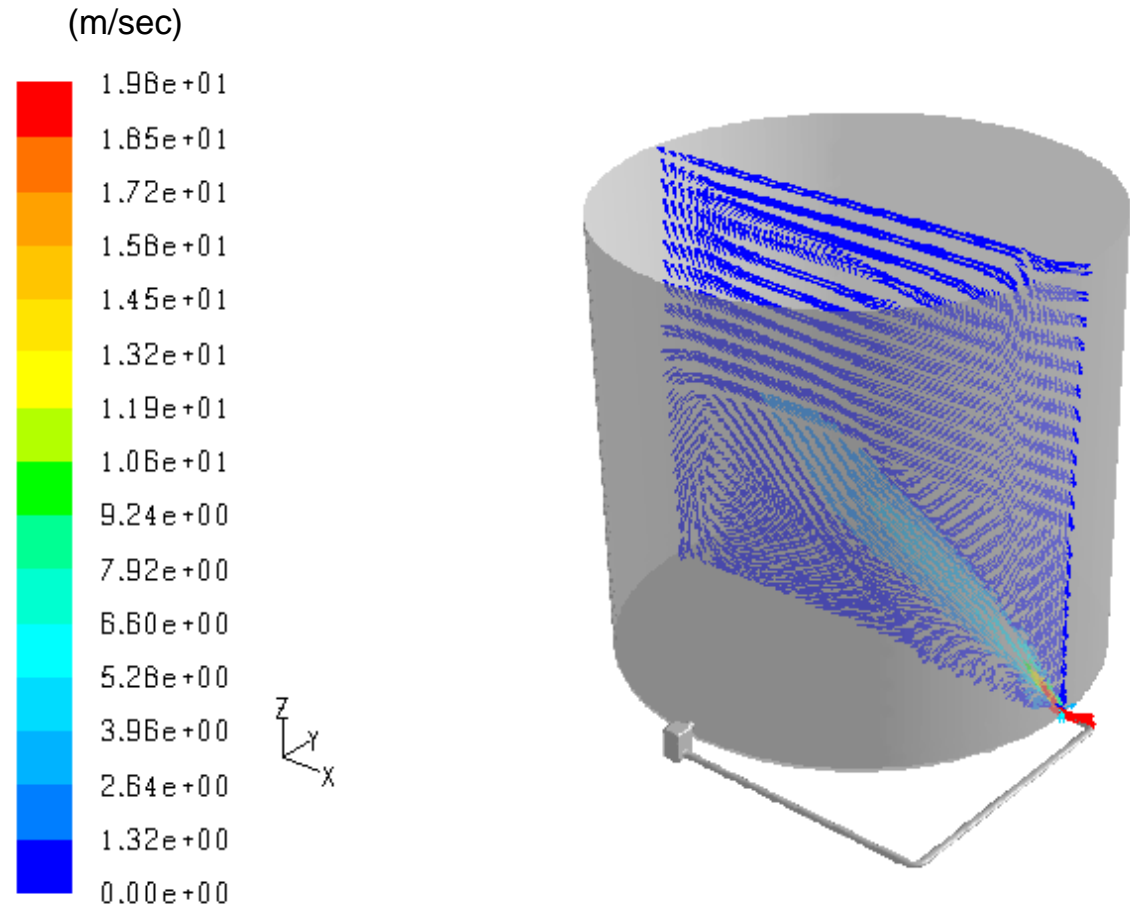

Figure 13. Fully developed flow patterns used as the initial flow conditions for the transient transport calculations using tracer species 


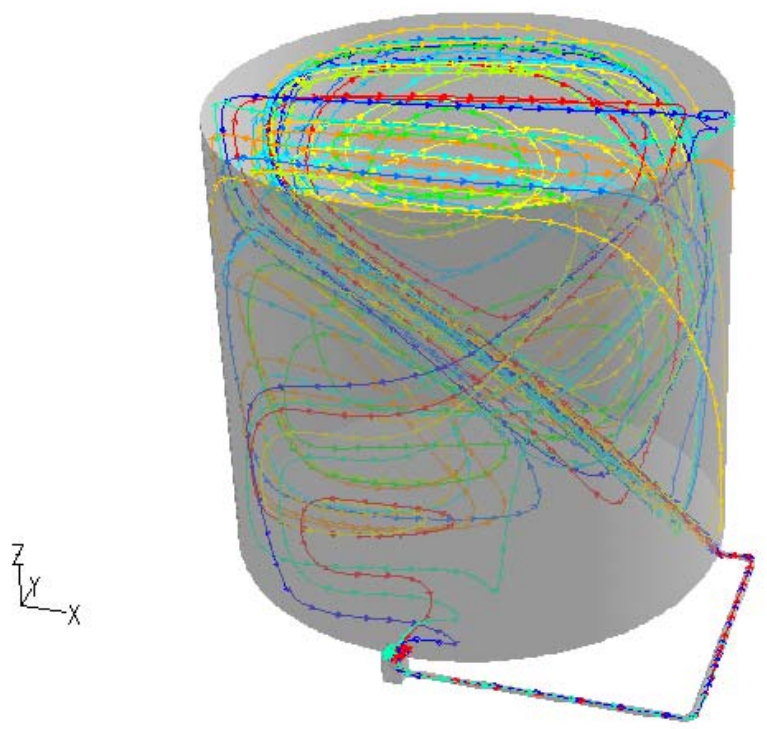

Figure 14. Lagrangian flow path lines from jet inlet to tank exit for fully developed flow circulation inside a tank during blending 
(Nondimensional species conc.)*
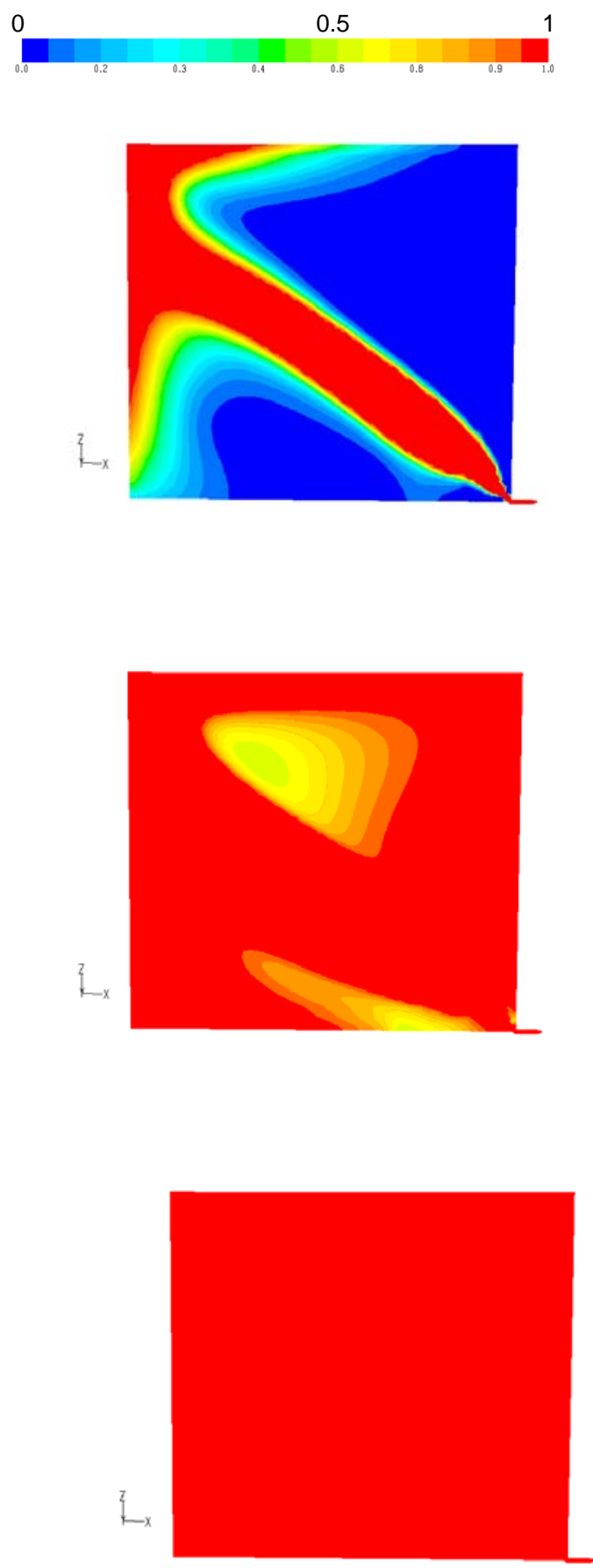

( $\mathrm{t}=33$ sec: blending time within 95\% homogeneity)

Figure 15. Comparison of transient time snapshots for flow patterns of species concentration at vertical central plane through the pump nozzle center line ( ${ }^{*}$ Non-dimensionalized by equilibrium species concentration of $3.02 \times 10^{-4}$; literature blending time results $=32$ seconds) 


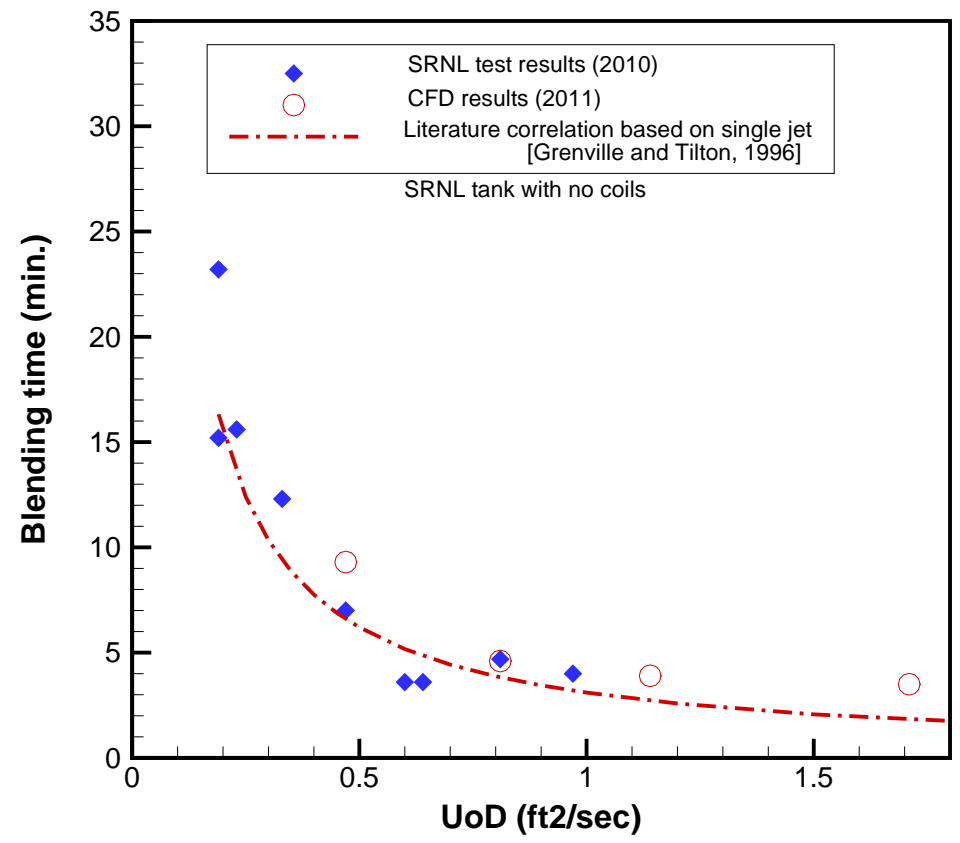

Figure 16. Benchmarking results of theoretical tank blending time compared to experimental test results [Ref. 9]

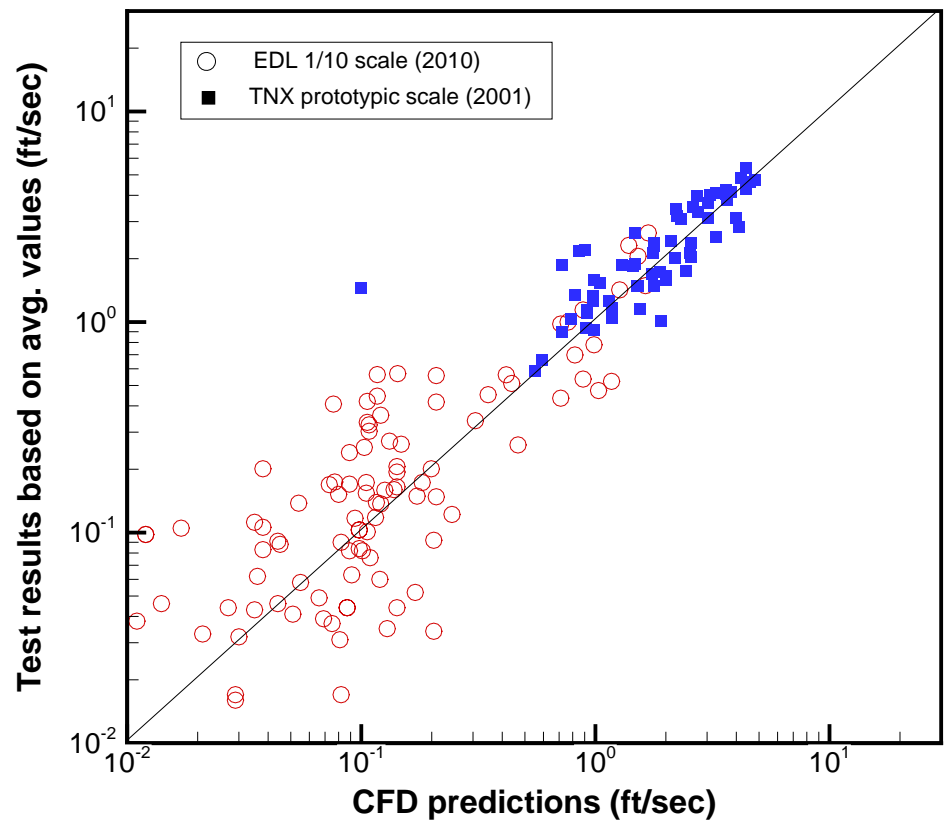

Figure 17. Benchmarking results of local fluid velocities compared to experimental test results [Ref. 9] 


\subsection{CFD PERFORMANCE, MODELING RESULTS}

As noted, the current work consisted of two main goals. One goal was to compute the blending time that adequately blends two miscible liquids. The other goal was to estimate the elevation in the tank at which the transfer pump inlet should be located to prevent excessive sludge entrainment during transfers.

Several figures describe the blending process in Tank 21. To do so, the steady-state flow field over the entire computational domain of the full-scale Tank 21 is shown in Figure 7, and calculations are performed using this mesh. Velocity flow patterns during blending are determined from the CFD models and are shown in Figure 18 at the discharge plane of the blender pump at 68.75 inches above tank floor. This figure shows that each of the dual jets of the submersible slurry pump forms a large circulation flow pattern as fluid momentum dissipates into the tank fluid media. Thus, the pump discharge plane has two unique, least active zones due to the formation of large circulation eddies, which is further clarified in Figure 19. More detailed circulation patterns can also be shown by the Lagrangian integration method along the flow path, where Figure 20 shows major flow path lines from the jet exit of the blending pump to the pump suction inlet.

\subsubsection{Blending Time Results}

Blending times are also determined from the CFD models. Figure 21 shows that when transient tracer concentrations are monitored at the tank center at the nozzle elevation, steady state tracer concentration reaches 95\% blending time at 38 minutes. Transient maximum and minimum concentrations during blending operations in Tank 21 are also shown in Figure 22, indicating that the required uncorrected blending time to reach 95\% homogeneity is again about 38 minutes. Figure 23 shows a comparison of the transient results for local fluid velocity, energy dissipation rate, flow circulation patterns, and species concentration distributions at the slurry pump discharge plane at the transient time of 5.5 minutes. Figure 24 presents transient snap shots for tracer concentrations at the pump discharge plane from the initial zero concentration to the quasi-steady concentration within 95\% homogeneity. The calculation results show that the blending time of the Tank 21 contents required for $95 \%$ homogeneity concentration is about 38 minutes. For final SDI Tank 21 blending time recommendations, this initial CFD estimate was increased by using a blending time correction factor to account for experimental deviations from CFD predictions, as calculated in Phase 2 Testing.

The modeling results clearly show that the turbulent jet dissipation rate and flow circulation behavior are closely related to the miscible fluid blending mechanisms within the tank fluid space. These results are consistent with the previous SRNL and literature results [Refs. 11, 12]. In particular, Baldyga and Bourne [11] developed an empirical correlation for blending time, $t_{\text {blend, }}$ in terms of eddy diffusivity $\left(v_{t}\right)$ and turbulent dissipation rate $(\varepsilon)$. That is

$t_{\text {blend }}=C\left(\frac{v_{t}}{\varepsilon}\right)^{0.5}$

A constant value of $C$ in Eq. (8) is dependent on turbulent flow conditions.

Tank 24 blending times are expected to be less than those calculated in the Phase 2 research. Accordingly, blending times calculated in Phase 2 research are recommended in the conclusions of this report. 
Also, Phase 2 research performed for the SDI project noted that bulk fluid additions may have effects on blending times not observed in the typical tracer additions that were used for most of the SDI research. In particular, three bulk addition tests were performed, where nearly half of the tank contents were removed. With two separate batches in each test, one batch could be spiked with acid, while the other was spiked with a base. Then, when the two batches were blended, and $\mathrm{pH}$ was monitored to establish blending times. Tests were set up to scale the flow rates of expected transfers into the blending tank from another tank. In other words, a scaled down flow rate of $75 \mathrm{gpm}$ was transferred into the receipt tank, using a scaled down three inch diameter, Schedule 40, nominal pipe size. On the one hand, results showed that when a denser salt solution was added to water, the transferring action blended the tank quite effectively. On the other hand, when water was added to a salt solution (Sodium nitrate, $\mathrm{NaNO}_{3}, 2.35$ centipoise, $1.257 \mathrm{~g} / \mathrm{ml}$ ), the salt solution stratified, and the stratified layer gradually decreased in level as the jets from the pump scoured the interface layer between the lighter and heavier fluids. For this specific case, the blending time was increased from a few hours for tracer additions to a few days, or more, for bulk additions for the case of water addition to salt solution. The effect of density on bulk addition blending times for other solutions was not further evaluated, and CFD modeling of this process was not investigated.

\subsubsection{Transfer Pump Results}

As discussed earlier, homogeneous blending of miscible salt solutions is required before operating transfer pumps to remove blended solutions to the SWPF. During the transient blending calculations, suspension of settled sludge is allowed since the blended tank contents will not transfer to the SWPF feed tank until the suspended solids are completely settled, where the solids settling time is evaluated in Section 6.0. Transfer pump CFD models tacitly assume that sludge has settled for 33 days, as discussed in the Phase 2 report.

The transfer pump models were developed to show that transferred solutions entrain minimal solids concentrations during transfer operation to the SWPF feed tank. In fact, although the SWPF feed criterion requires the solids entrainment to be less than $1200 \mathrm{mg} / \mathrm{l}$, the transfer pump model conservatively assumes that no solids are transferred, using the Phase 2 velocity determined to prevent sludge entrainment at $0.022 \mathrm{ft} / \mathrm{sec}$ [Ref. 9]. As shown in Figures 8 and 9, the computational domain does not include the sludge region, and the model assumes the top surface of the sludge layer interface to be frictionless. Detailed modeling conditions for the transfer pump operations in Tank 21 and Tank 24 are summarized in Table 2.

For the Tank 21 Hazelton pump, a bottom plate is not installed and a 3 inch diameter suction inlet is located at 52.9 inches above the sludge layer. For this design, Figure 25 shows steady state flow patterns, where $100 \mathrm{gpm}$ is transferred through the pump. Velocity distributions on the top surface of the sludge layer due to the Hazelton pump in Tank 21 are presented in Figures 26 and 27.

For the Tank 24 Tsurumi transfer, a 10.5 inch diameter solid plate is located 3.5 inches below the pump inlet and 9 inches above sludge layer as shown in Figure 9. Flow patterns are shown in Figure 28 during transfer operations for a $100 \mathrm{gpm}$ flow rate through a 3.11 inch diameter suction inlet. Flow directions and velocity magnitudes on the top surface of the 
sludge layer due to the Tsurumi pump operation in Tank 24 is presented in Figures 29 and 30.

To compare Tank 21 Hazelton and Tank 24 Tsurumi transfer pumps, quantitative maximum sludge surface velocities are provided in Table 4 , and velocities along the pump center line at the top surface of the sludge layer are shown in Figure 31. As shown in the table, when the Hazelton transfer pump without a solid plate is placed 52.9 inches above the sludge layer, the maximum local velocity on the top surface of sludge layer is $0.0013 \mathrm{ft} / \mathrm{sec}$. For the Tsurumi pump with a solid plate located 9 inches above sludge layer, the maximum sludge surface velocity is $0.013 \mathrm{ft} / \mathrm{sec}$ for the transfer operation. In short, the maximum velocity at the top surface of the sludge layer for either pump does not exceed the acceptance criterion of no sludge entrainment at $0.022 \mathrm{ft} / \mathrm{sec}$. These calculation results demonstrated that no solids from the sludge layer settled on the tank floor will be entrained during transfers to the SWPF feed tanks at flow rates of $100 \mathrm{gpm}$, using the Tank 21 Hazelton and Tank 24 Tsurumi transfer pumps with the operating conditions specified in Table 2. Only solids in suspension at the time of transfer initiation will be transferred, and those suspended solids depend on the settling characteristics of the sludge.

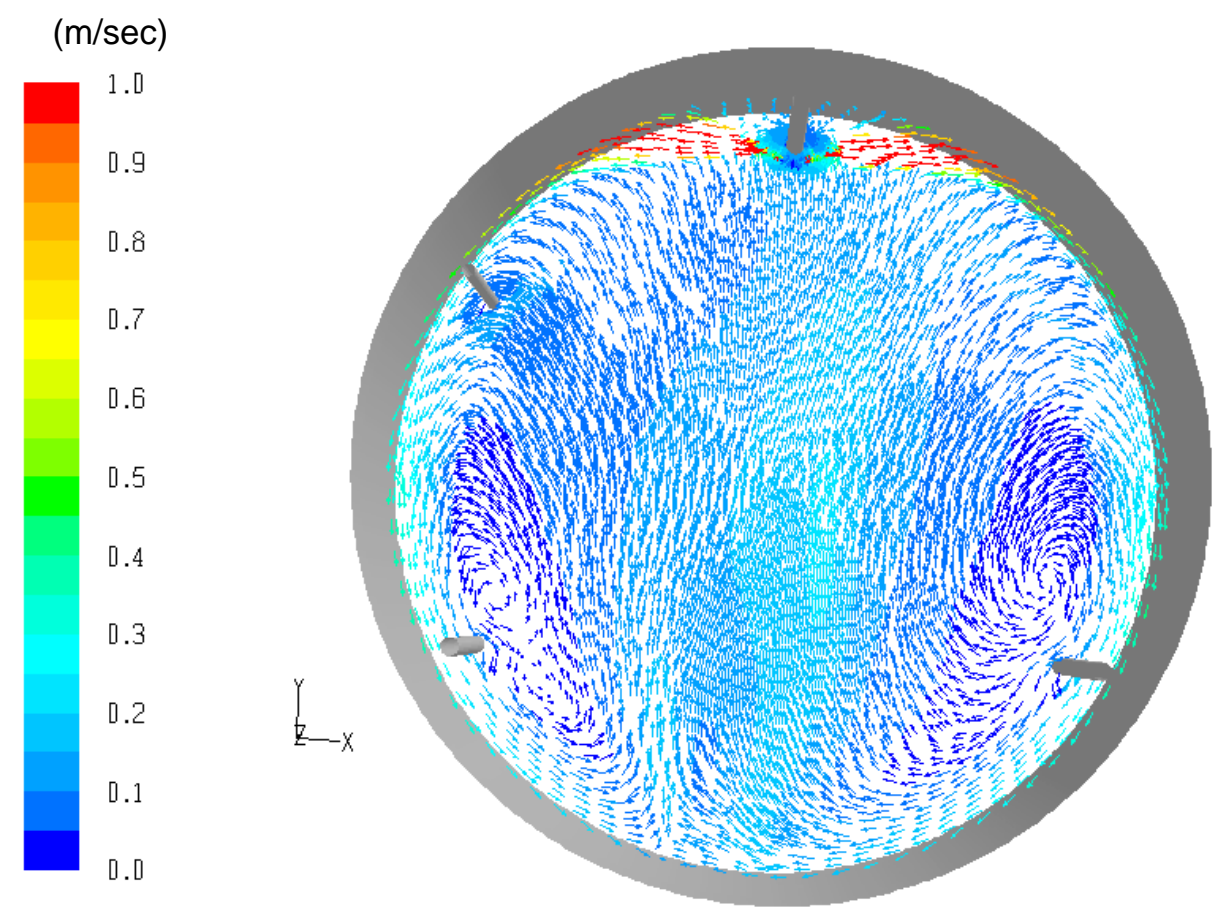

Figure 18. Steady state flow patterns at the discharge plane elevation of the slurry pump 

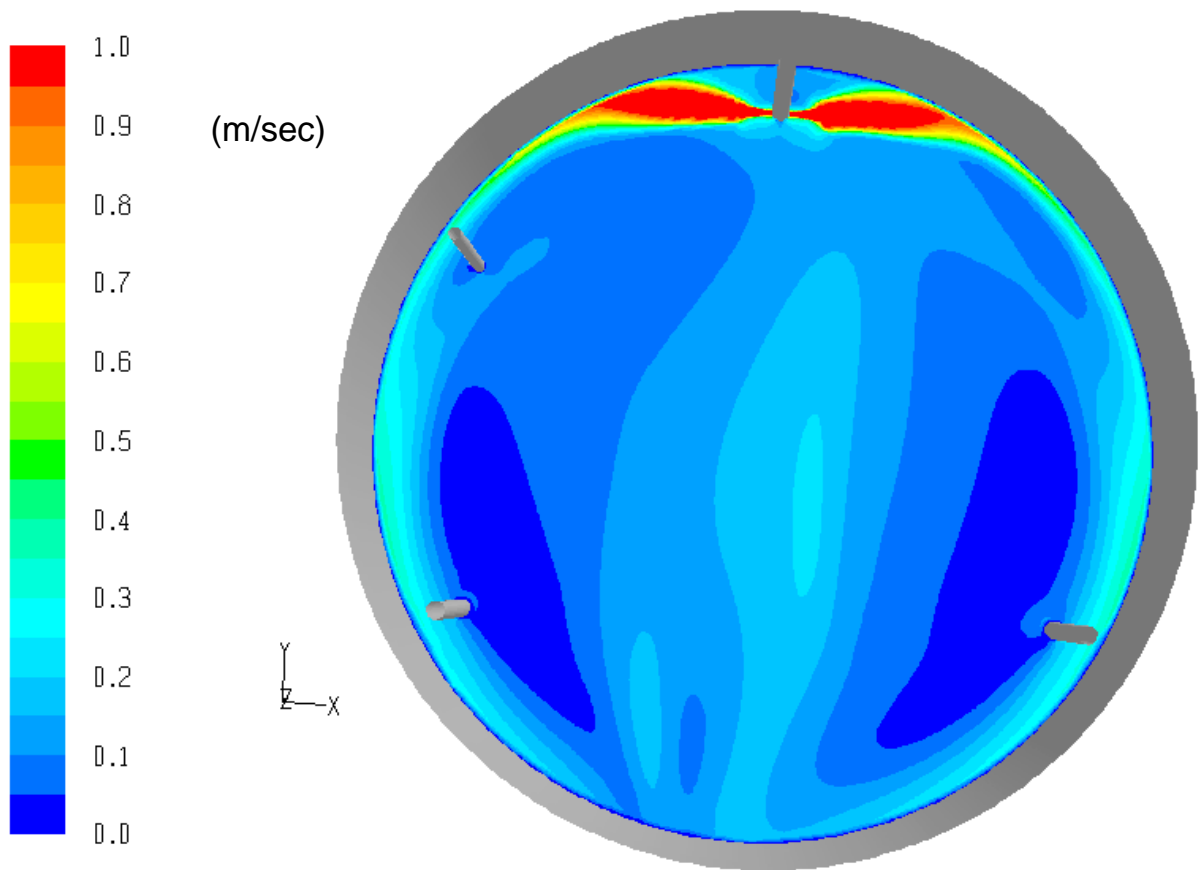

Figure 19. Steady state flow distributions at the discharge plane elevation of the slurry pump

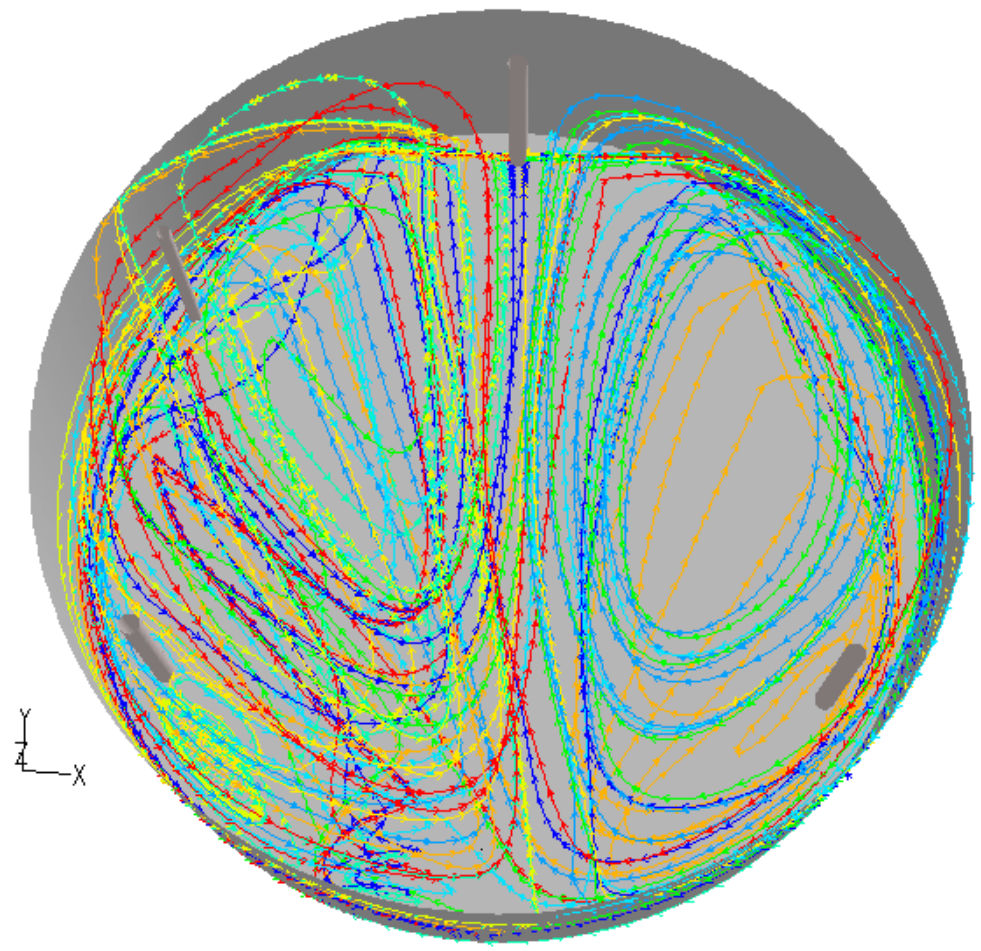

Figure 20. Lagrangian flow circulation patterns for fully developed flow circulation inside the tank 


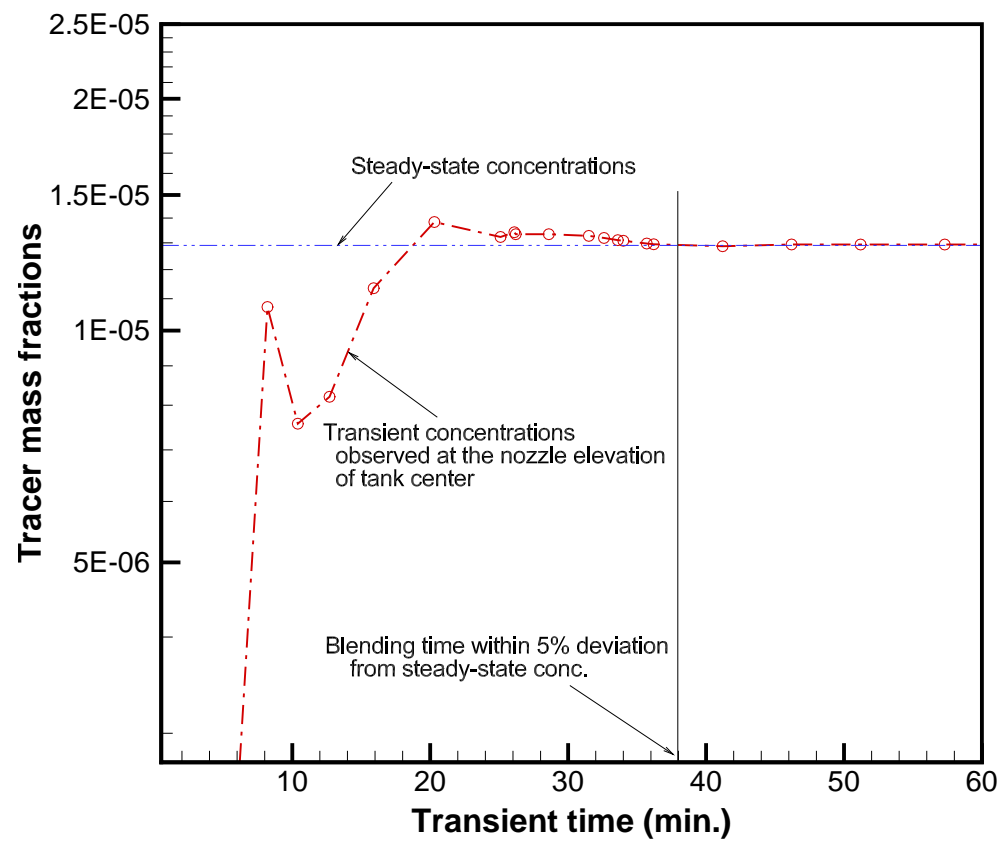

Figure 21. Transient concentrations at an observation point at the tank center and pump elevation

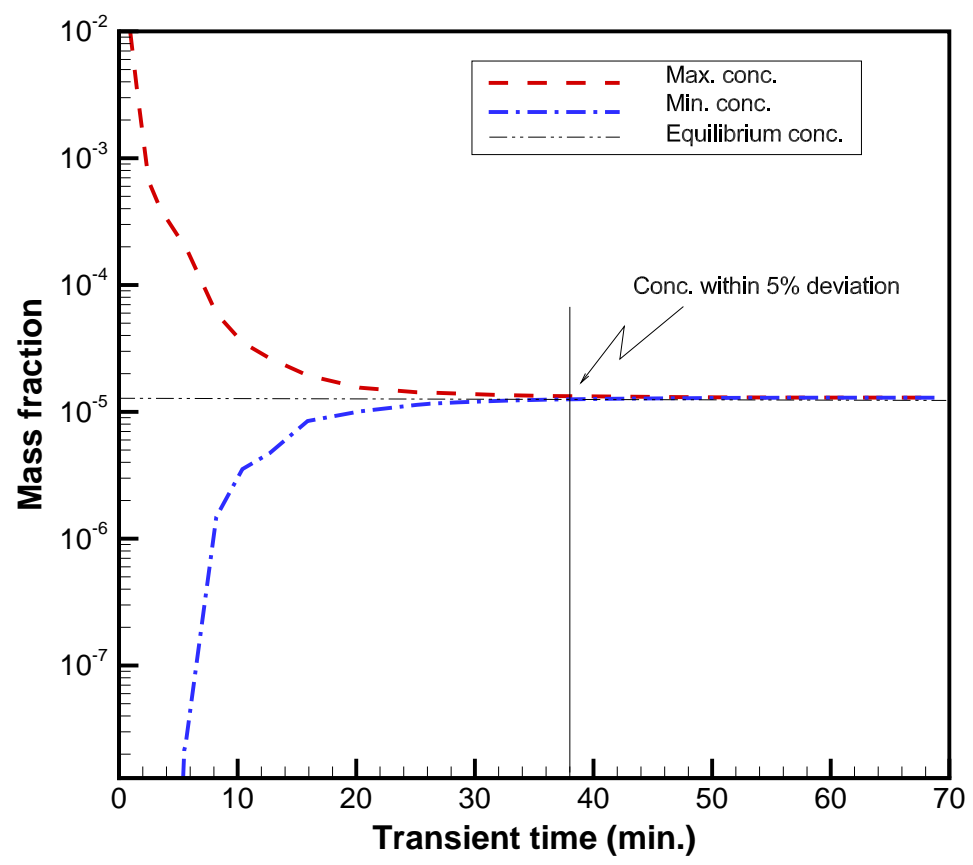

Figure 22. Transient maximum and minimum concentrations during blending operations in Tank 21 

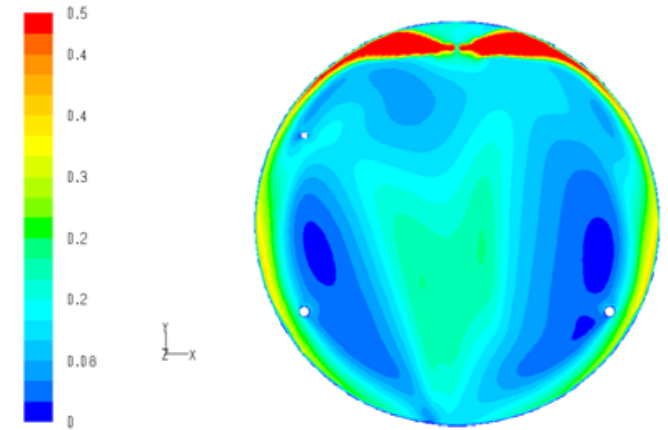

(Velocity magnitude, numbers in $\mathrm{m} / \mathrm{sec}$ )
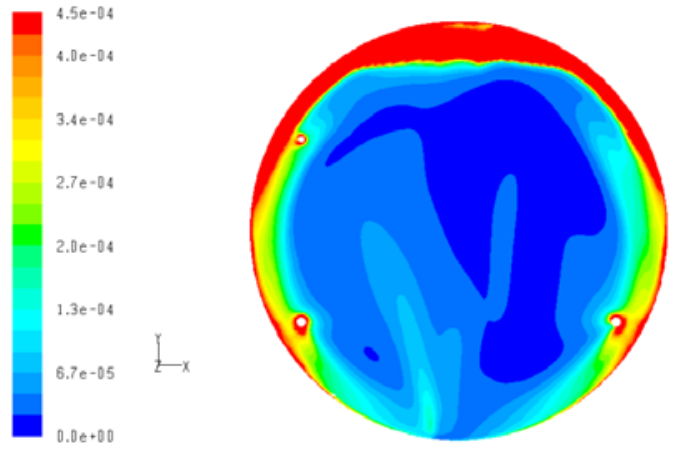

(Energy dissipation rate, numbers in $\mathrm{m}^{2} / \mathrm{sec}^{3}$ )

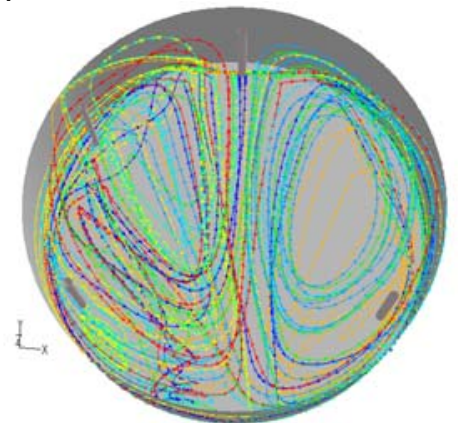

(Lagrangian flow circulation patterns)
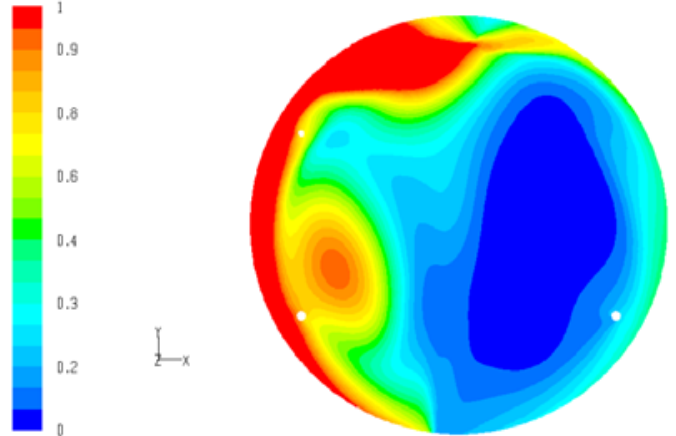

(Species concentration non-dimensionalized by equilibrium value)

Figure 23. Comparison of the transient results for fluid velocity, energy dissipation rate, flow circulation patterns, and species concentration distributions at the slurry pump discharge elevation plane at the transient time of 5.5 minutes 


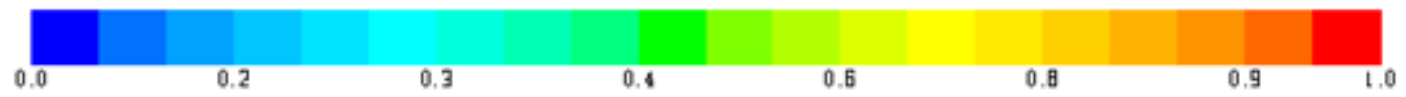

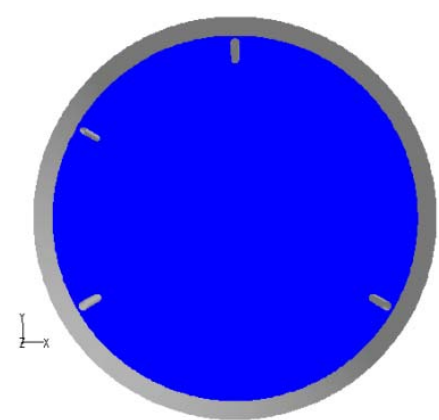

(0 min.)

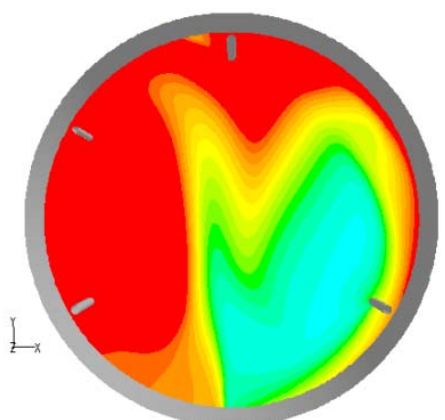

(10.4 $\mathrm{min}$.

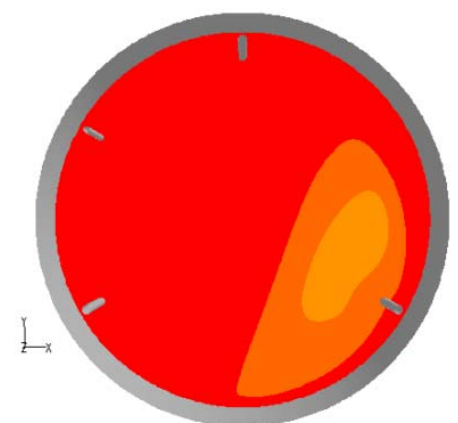

(25.1 $\mathrm{min}$.

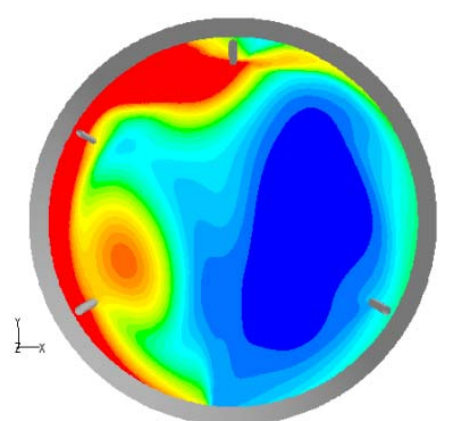

(5.5 min.)

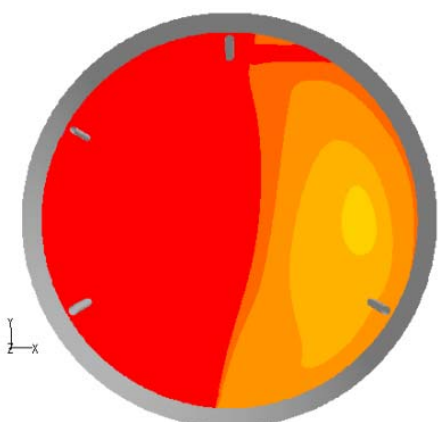

(20.3 min.)

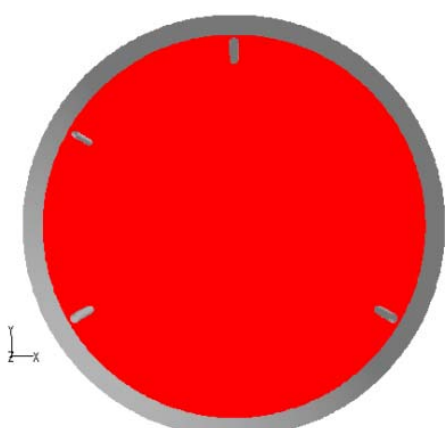

(41.2 $\mathrm{min}$.

Figure 24. Transient non-dimensionalized concentration distributions on the pump discharge plane 


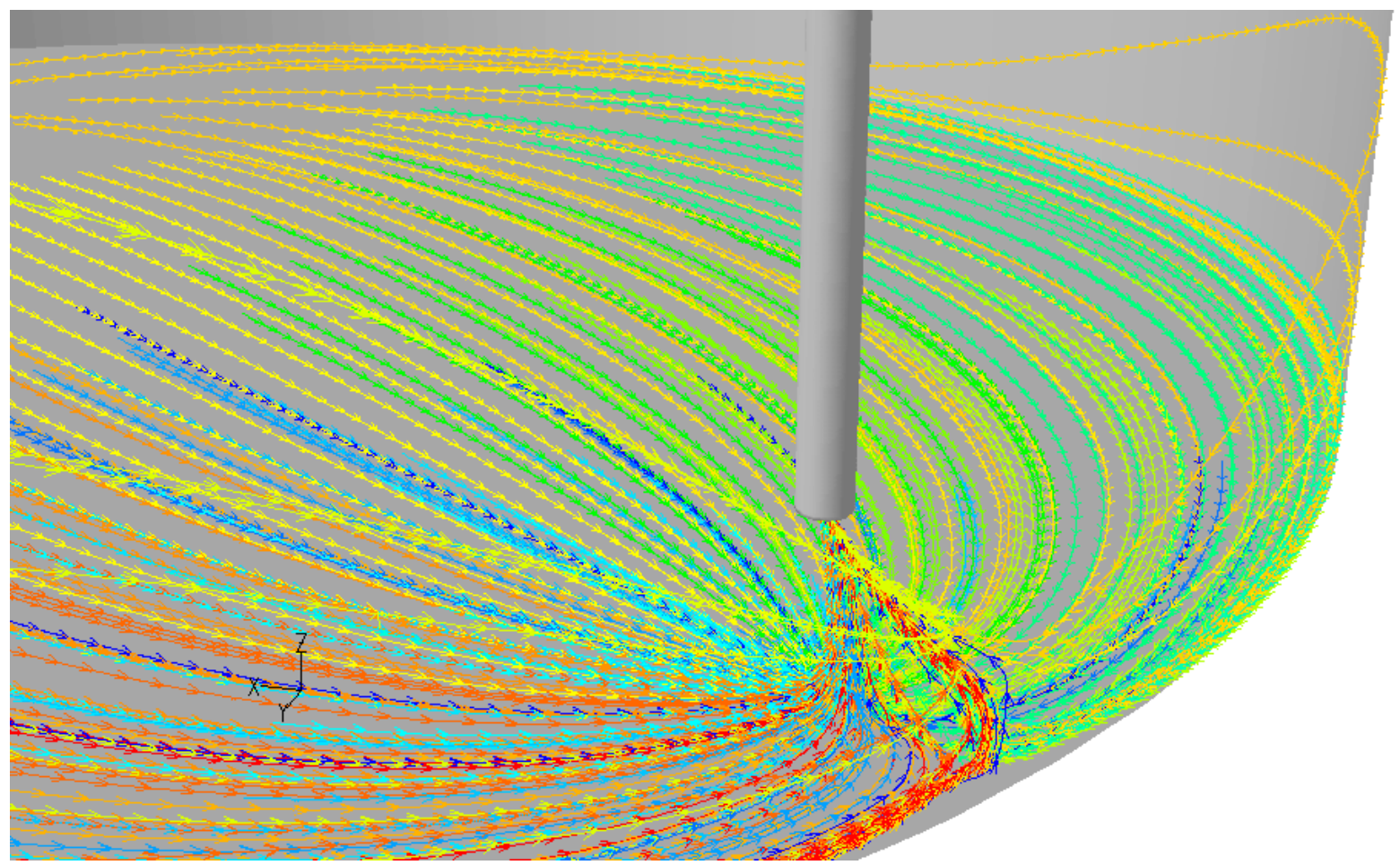

Figure 25. Typical flow patterns near the transfer pump inlet in Tank 21 as shown by Lagrangian integration along the fluid flow paths

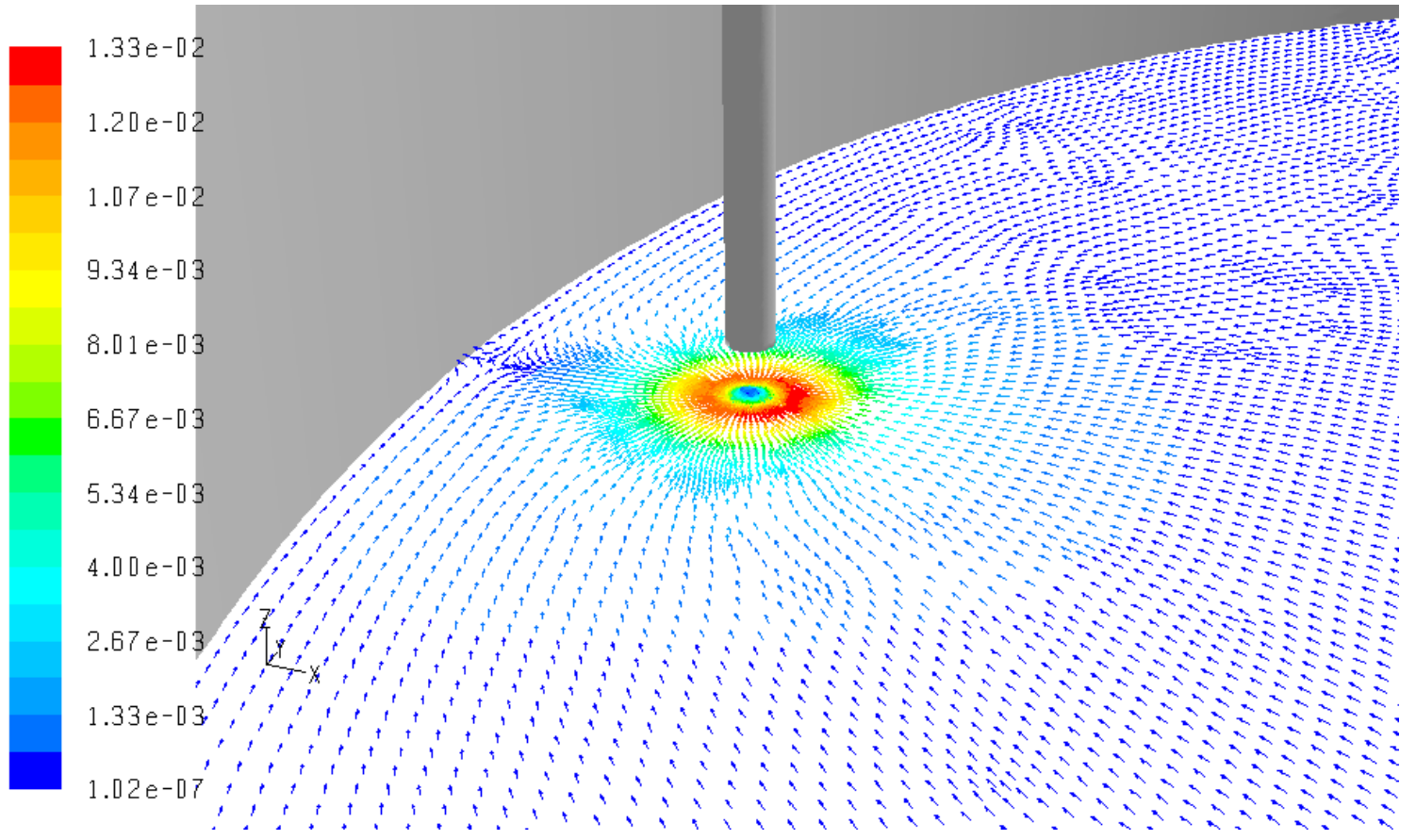

Figure 26. Flow patterns on the top surface of the sludge layer in Tank 24 (100 gpm flowrate) 
$(\mathrm{ft} / \mathrm{sec})$

$1.31 \mathrm{e}-03$
$1.18 \mathrm{e}-03$
$1.05 \mathrm{e}-03$
$9.18 \mathrm{e}-04$
$7.86 \mathrm{e}-04$
$6.55 \mathrm{e}-04$
$5.24 \mathrm{e}-04$
$3.93 \mathrm{e}-04$
$2.62 \mathrm{e}-04$
$1.31 \mathrm{e}-04$
$0.00 \mathrm{j}+00$

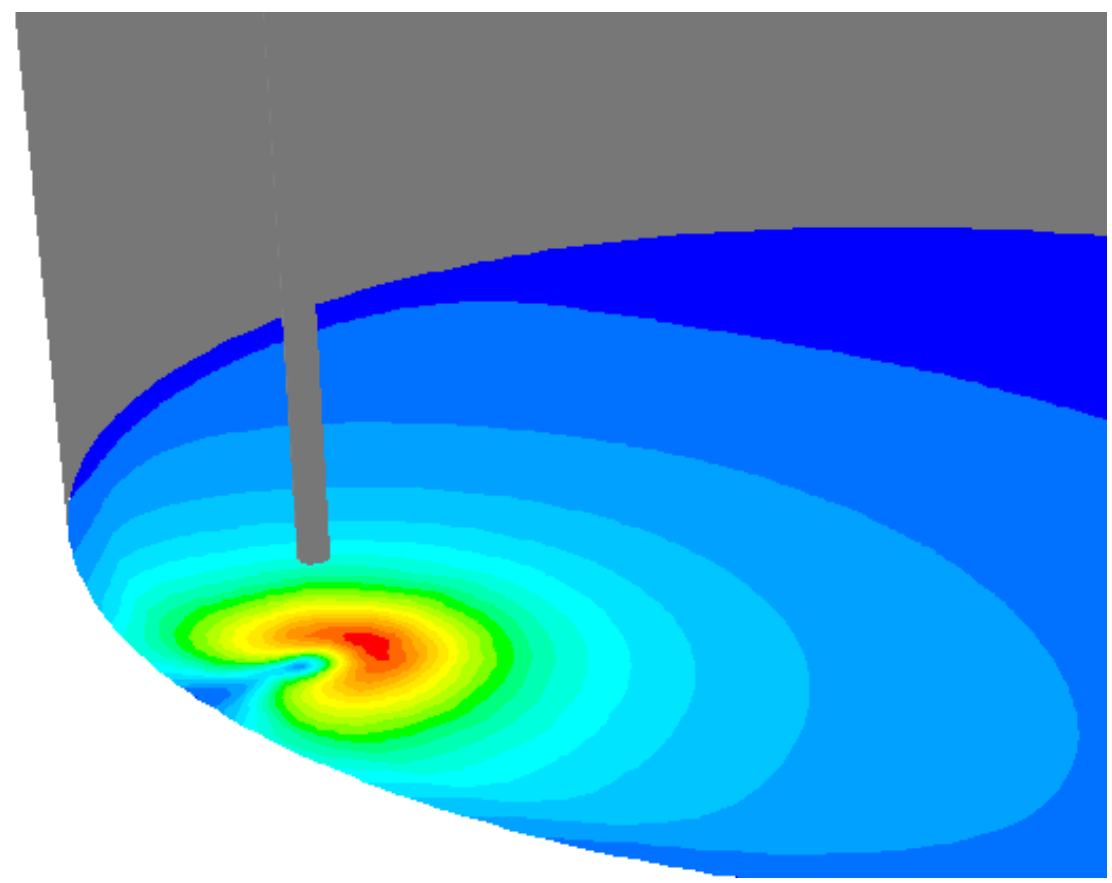

Figure 27. Flow rate distributions for Tank 21 (ft/sec)

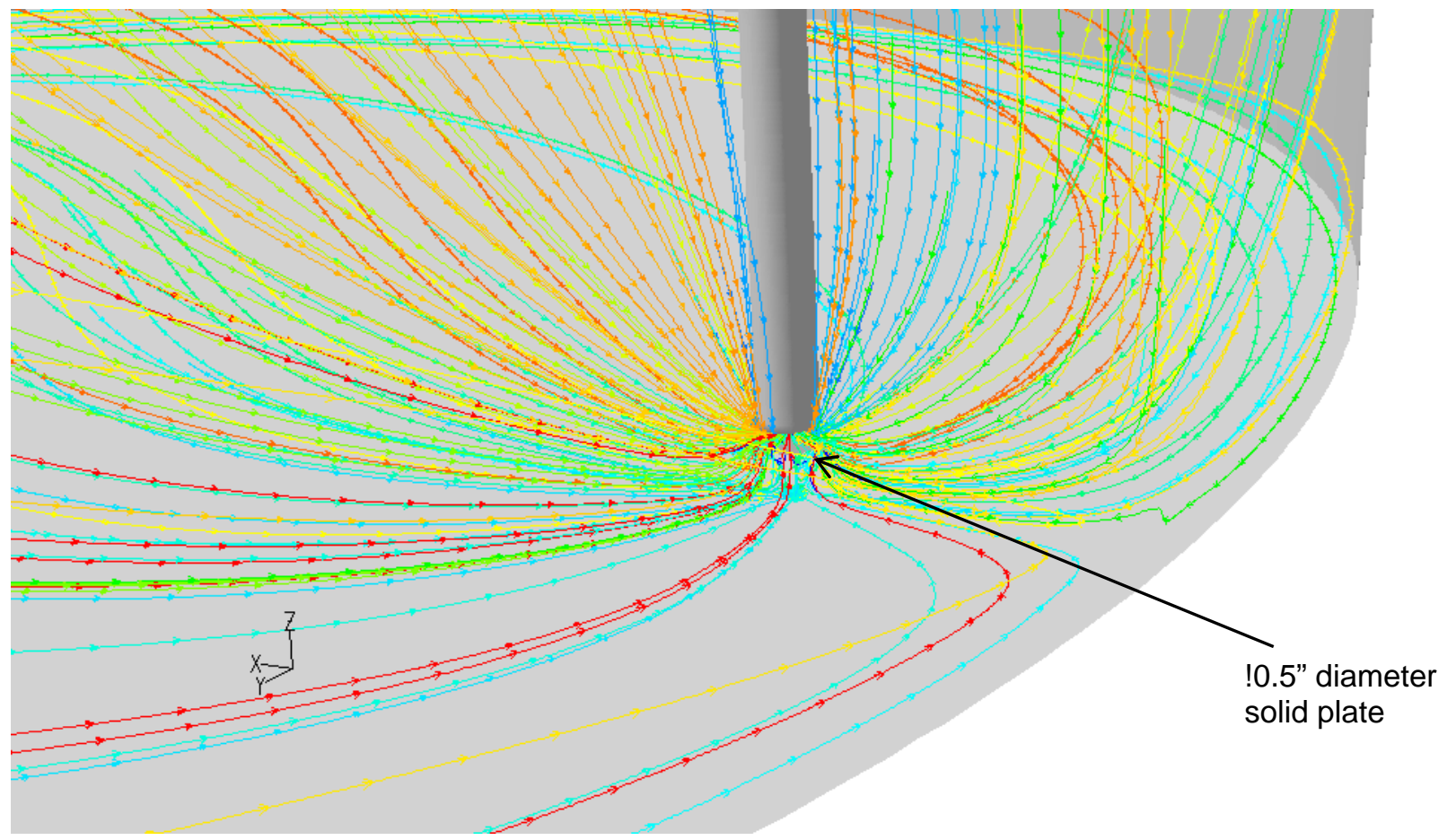

Figure 28. Typical flow patterns near the transfer pump inlet with solid plate in Tank 24 as shown by Lagrangian integration along the fluid flow paths 


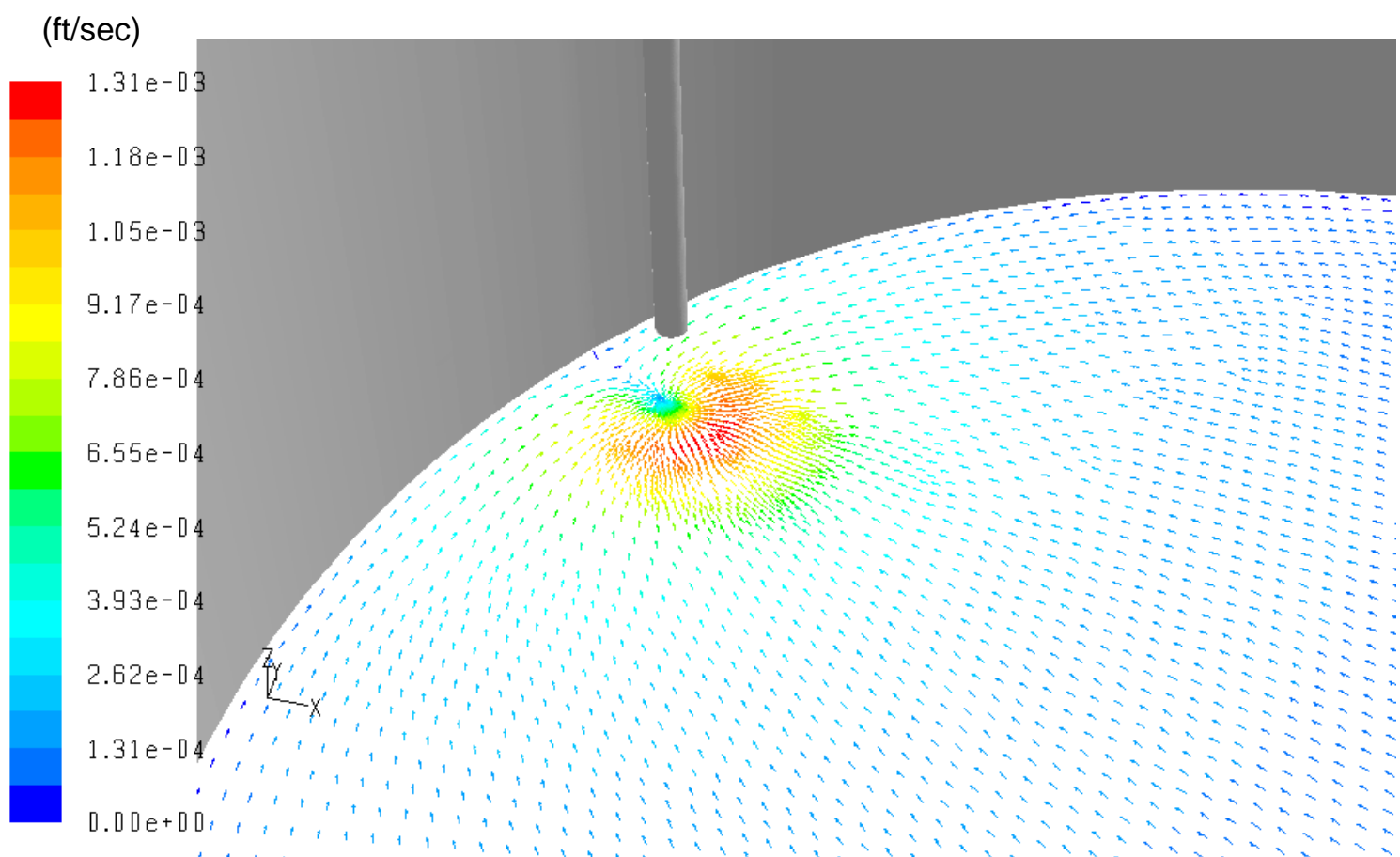

Figure 29. Flow patterns on the top surface of the sludge layer in Tank 21 (100 gpm transfer flowrate)
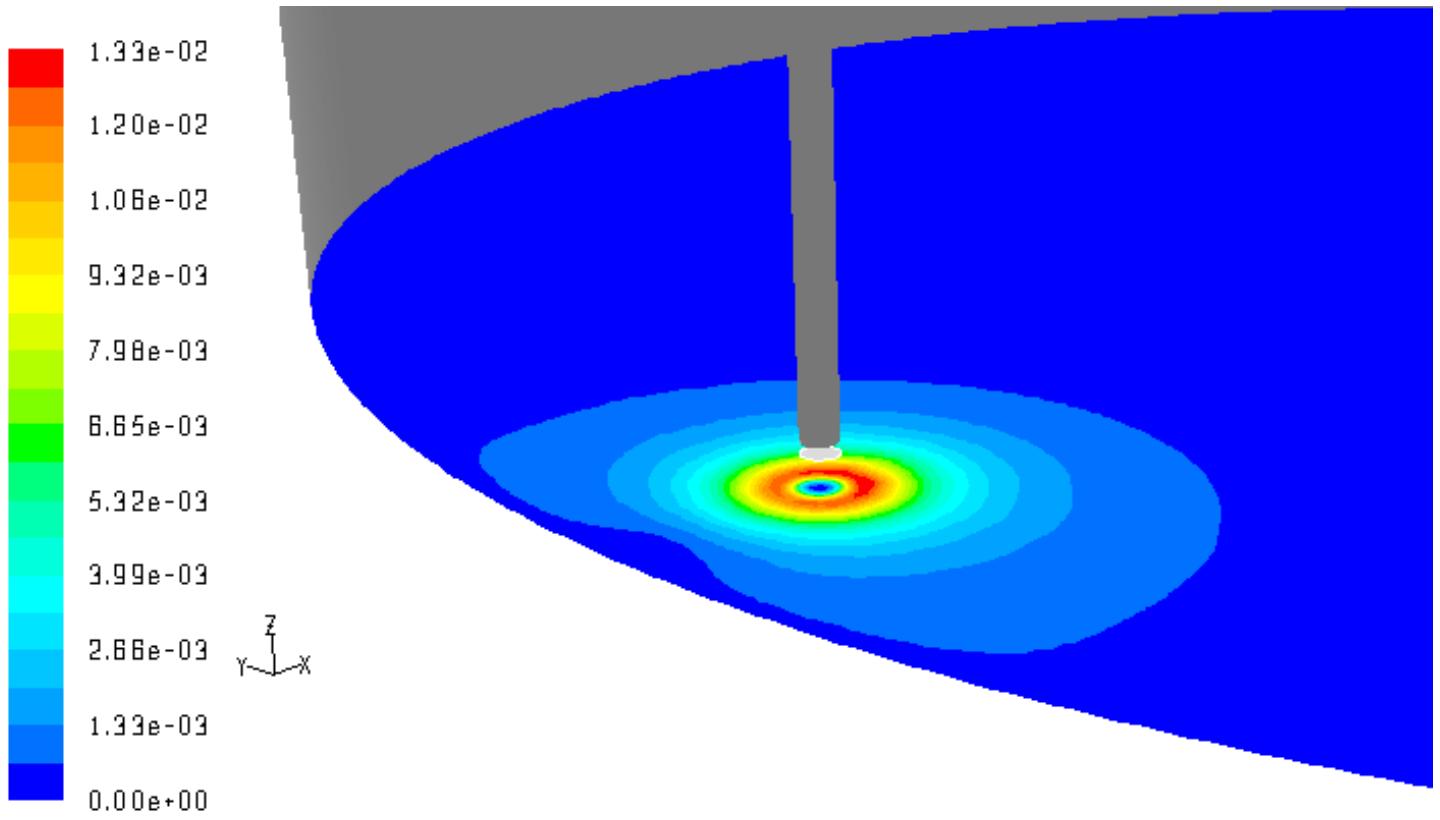

Figure 30. Flow rate distributions for Tank 24 (ft/sec) 


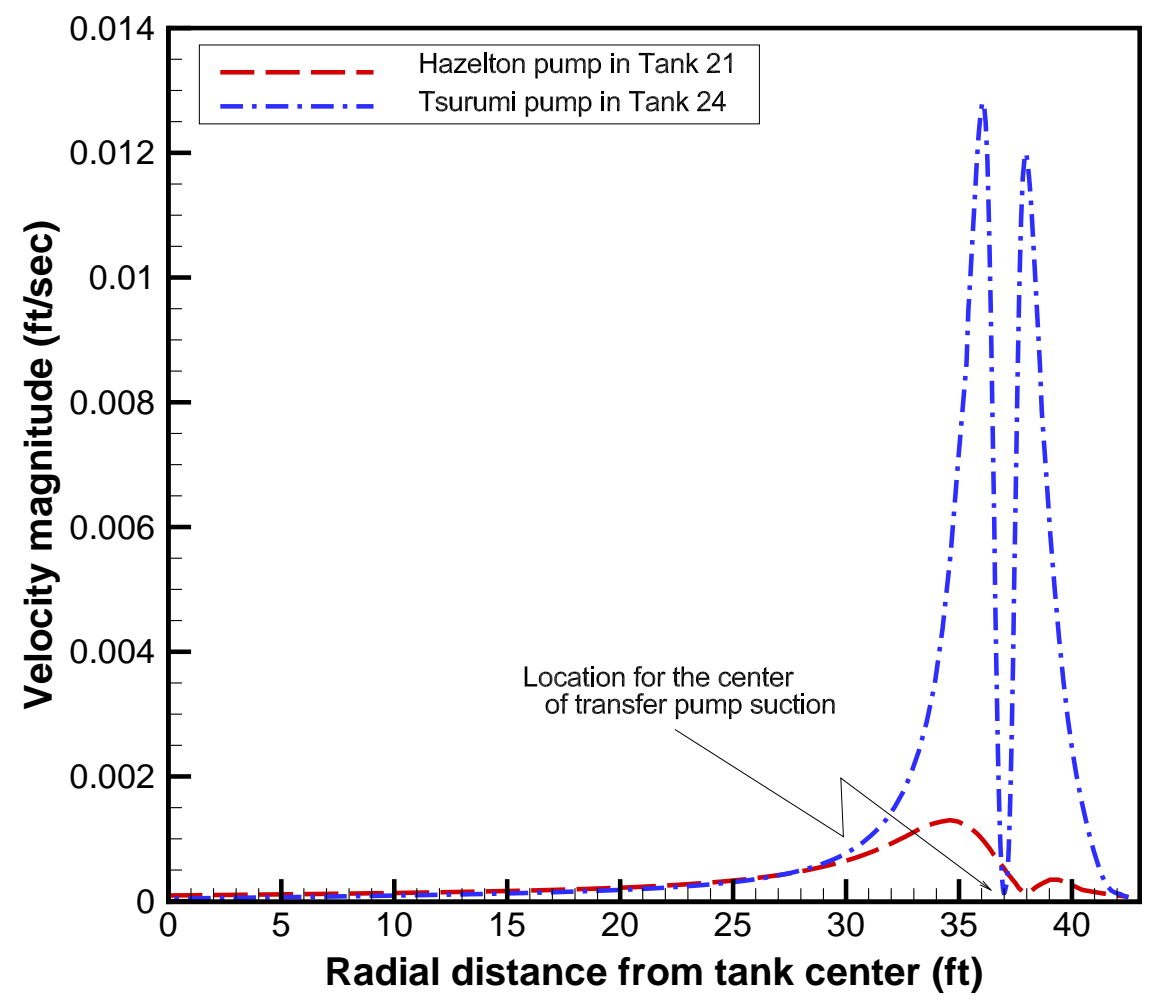

Figure 31. Velocity profile for each pump along the tank radial center line at the top surface of the sludge layer

Table 4. Comparison of maximum velocity magnitudes on the top sludge surface

\begin{tabular}{|c|c|c|c|}
\hline Tank & Transfer pump & $\begin{array}{c}\text { Separation distance } \\
\text { between suction } \\
\text { inlet and top sludge } \\
\text { surface, inches }\end{array}$ & $\begin{array}{c}\text { Maximum velocity } \\
\text { magnitude at top } \\
\text { surface of sludge } \\
\text { layer, ft/sec }\end{array}$ \\
\hline Tank 21 & Hazelton & 52.9 & 0.0013 \\
\hline Tank 24 & Tsurumi & $12.5\left(9^{\star}\right)$ & 0.0133 \\
\hline
\end{tabular}

Note:*Vertical distance between solid plate and top sludge surface 


\subsection{SETTLING TIME CALCULATIONS}

The particle settling velocity is calculated by the following equations

$v_{s}=g(s-1) d_{p}{ }^{2} / 18 v \quad$ for $\operatorname{Re}_{p}<1.4$

$v_{s}=0.13[g(s-1)]^{0.72} d_{p}^{1.18} v^{-0.45}$ for $1.4<\operatorname{Re}_{p}<500$

$\mathrm{V}_{\mathrm{s}}=1.74\left[\mathrm{~g}(\mathrm{~s}-1) \mathrm{d}_{\mathrm{p}}\right]^{0.5} \quad$ for $\mathrm{Re}_{\mathrm{p}}>500$

$\operatorname{Re}_{p}=d_{p} v_{s} / v$

where $v_{s}$ is the settling velocity, $g$ is the acceleration due to gravity, $s$ is the ratio of particle and fluid densities ( $s=$ particle density/fluid density), $d_{p}$ is the particle diameter, $\mu$ is fluid viscosity, $\rho$ is fluid density, and $v$ is the fluid kinematic viscosity $(v=\mu / \rho)$ [Ref. 16].

To perform the calculation, one assumes a particle Reynolds number $\left(R e_{p}\right)$, calculates the settling velocity with the appropriate equation, and calculates a new particle Reynolds number with the calculated settling velocity. If the Reynolds number is in the correct range for the equation used, the calculated settling velocity is correct. If the Reynolds number is not in the correct range for the equation used, a different equation is used to calculate the settling velocity. These steps are repeated as necessary.

The following supernate and sludge properties were used to perform the particle settling calculations:

- The supernate density is $1.25 \mathrm{~g} / \mathrm{mL}$. Based on $5.6 \mathrm{M}$ sodium salt solution.

- The supernate viscosity is $3 \mathrm{cP}$. Based on $5.6 \mathrm{M}$ sodium salt solution.

- The sludge particle density is $2.5,3.0,4.0$, and $5.0 \mathrm{~g} / \mathrm{mL}$. The densities were selected to represent particle densities of compounds expected in SRS sludge (gibbsite, $2.4 \mathrm{~g} / \mathrm{mL}$; ferric hydroxide, 3.4 - $3.9 \mathrm{~g} / \mathrm{mL}$; aluminum oxide, $4.0 \mathrm{~g} / \mathrm{mL}$; hematite, $5.1 \mathrm{~g} / \mathrm{mL}$ ) [Ref. 17]. Observations of SRS sludge have suggested a sludge particle density of $2.5-2.7 \mathrm{~g} / \mathrm{mL}$.

- A tank liquid level of 345 inches was assumed.

To achieve the salt waste processing throughput assumed in the Liquid Waste System Plan, approximately one million gallon batches of blended salt solution will be qualified as feed to the Salt Waste Processing Facility. A key criterion for acceptable SWPF feed is for the sludge solids content to be $<1200 \mathrm{mg} / \mathrm{L}$. The batch qualification duration is expected to be between 30 and 60 days. Any settled solids in the blend tank disturbed during the batch preparation phase must settle during the 30-60 day qualification period to ensure the solids criterion is met prior to transfer to SWPF.

Figure 32 shows the calculated settling velocity of the sludge particles as a function of particle size and density. The figure shows that particles less than or equal to $2 \mu \mathrm{m}$ in diameter have a settling velocity less than 10 inches per day and could take more than 30 days to settle 345 inches. Particles larger than $10-15 \mu \mathrm{m}$ in diameter have a settling velocity greater than 100 inches per day and would take less than 3.5 days to settle 345 inches. The figure also shows that the settling velocity is a function of particle size and particle density. 


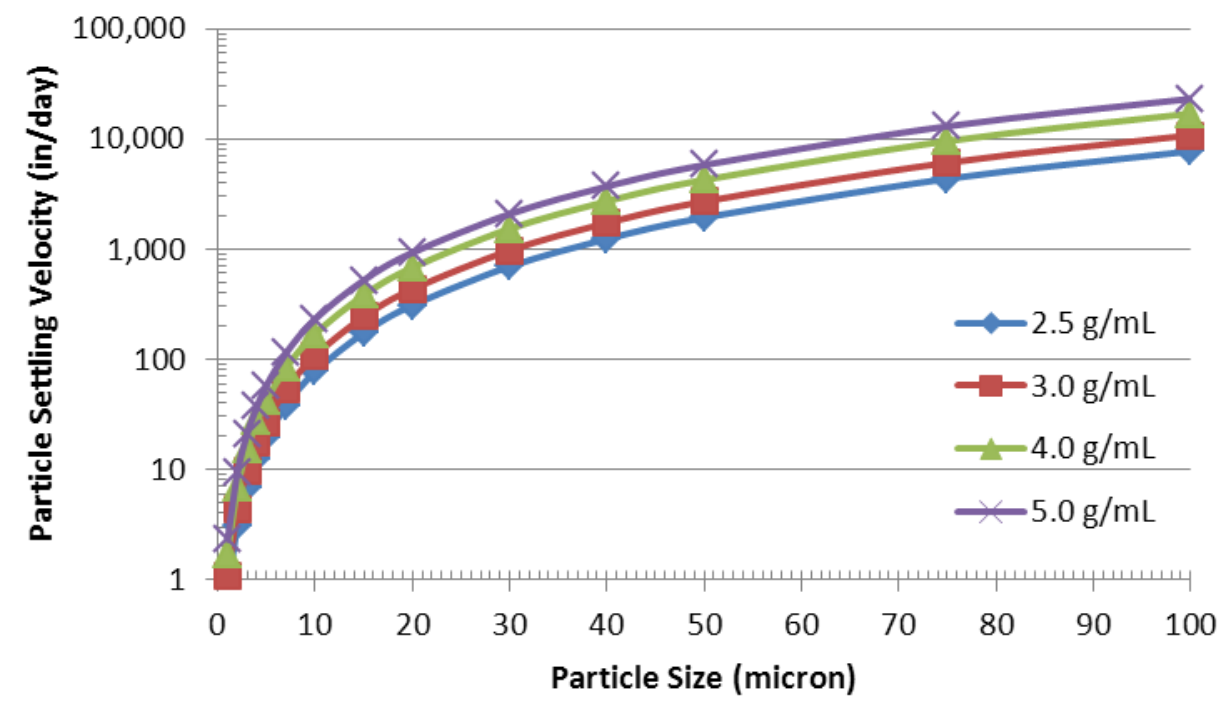

Figure 32. Settling velocity of sludge particles as a function of particle size and density

Figures 33 and 34 show the time required for sludge particles to settle 345 inches. The figures show that particles less than $2-4 \mu \mathrm{m}$ in diameter would take longer than 30 days to settle 345 inches. Particles larger than $12-21 \mu \mathrm{m}$ would take less than 1 day to settle 345 inches.

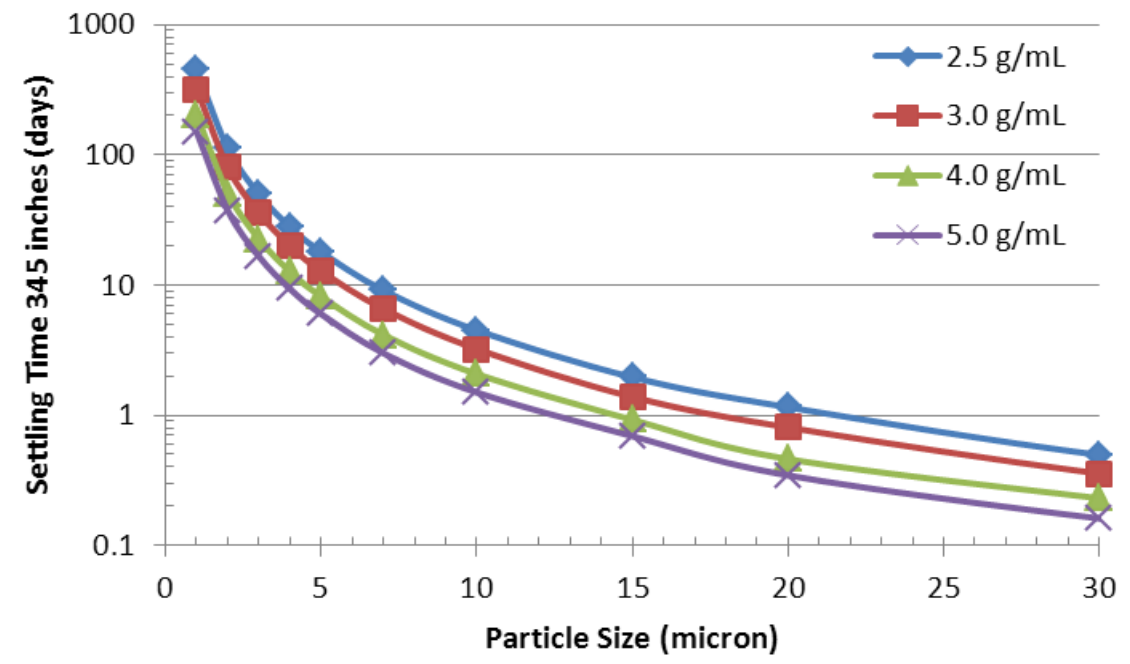

Figure 33. Time for sludge particle to settle 345 Inches 


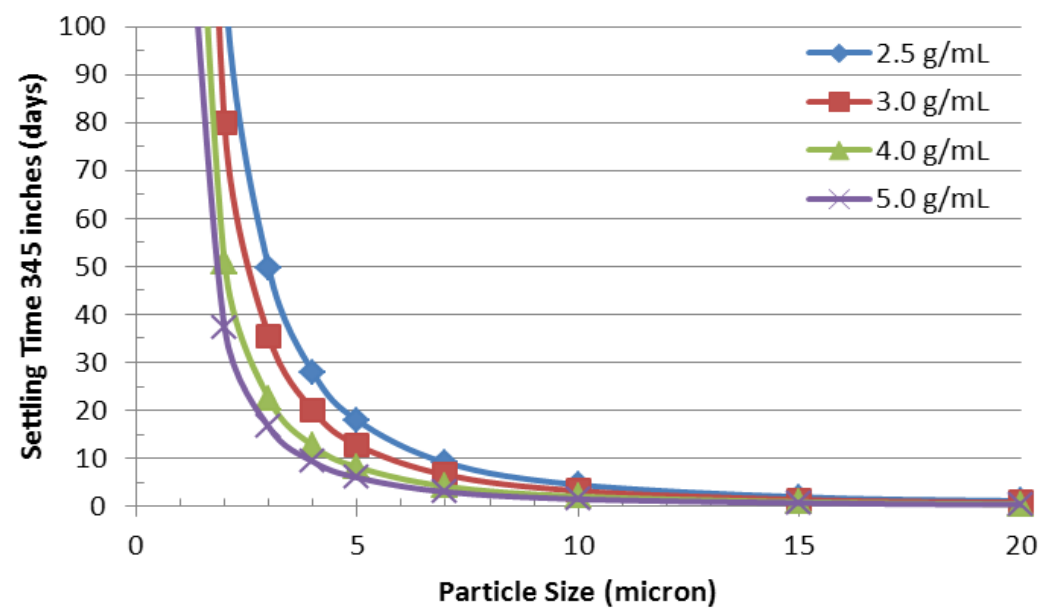

Figure 34. Time for sludge particle to settle 345 Inches

Figure 35 shows data on measured sludge particle size [18]. The figure shows a median particle size of $2.5-15 \mu \mathrm{m}$, and $30 \%$ of the particles less than $1.5-7 \mu \mathrm{m}$. These results show that SRS waste tanks could contain a significant fraction of sludge particles with diameter less than $3 \mu \mathrm{m}$.

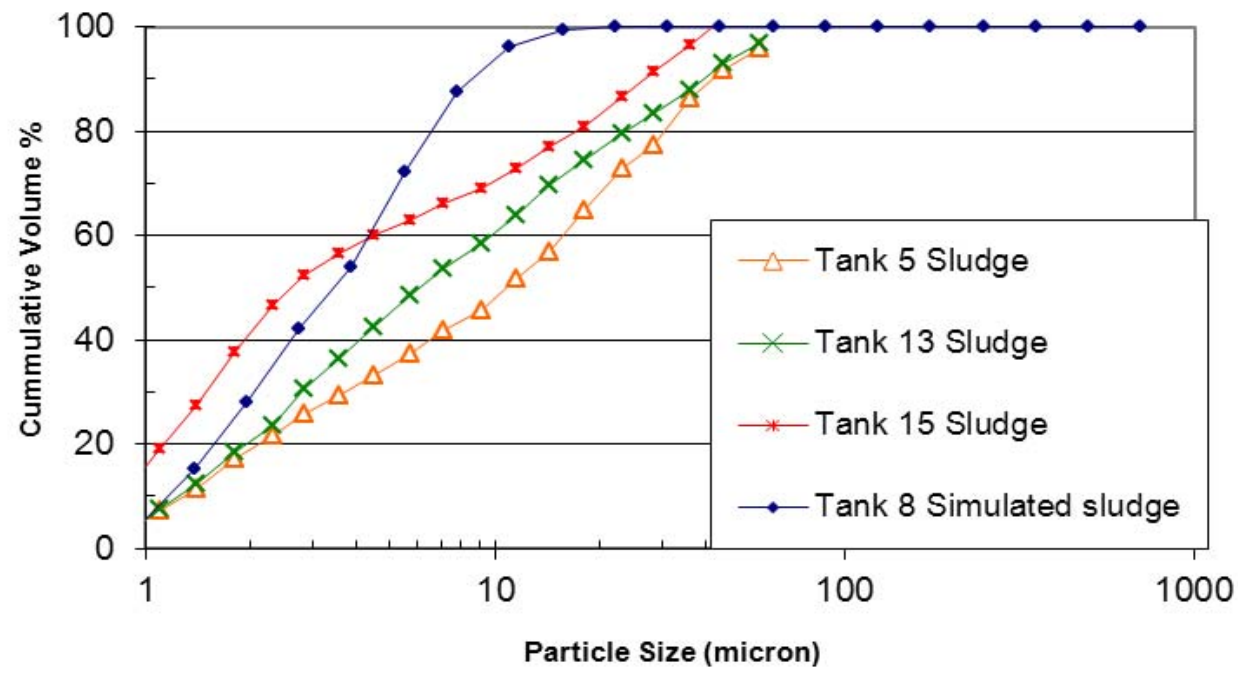

Figure 35. Particle size of actual SRS sludge

Figures 2-3, 2-4, 2-5, and 2-6 in reference 2 [SRNL-STI-2011-00151] show the particle size of the simulated sludge batch 6 used in previous testing. The analysis shows $30-40 \%$ of the particles were less than $3 \mu \mathrm{m}$. Testing with simulated sludge batch 6 showed the solid particles settled 330 inches in approximately 100 hours. This settling time ( 4 days) is much less than the settling time predicted for particles less than $3 \mu \mathrm{m}$ in Figure $34(14-43$ days). The likely cause of this difference is that the particles in the settling test were larger than the particles in the particle size analysis. The settling test contained a feed with 
approximately 2.5 vol\% solid particles ( 1 wt \%) that settled to 9 inches in 350 inches. The samples analyzed for particle size contained less than $0.1 \mathrm{wt} \%$ solid particles. At the higher concentration, the particles are likely to agglomerate and form larger particles that would settle more rapidly.

Per SRR engineering, a similar settling behavior was observed in recent Tank 21 salt batch preparation for the Integrated Salt Disposition Process (ISDP) in H-Tank Farm. Standard slurry pumps were operated for a total of 28 hours over a several day period to mix trim chemicals into the bulk salt solution. Turbidity measurements were made 128 hours (approximately 5 days) after mixing was concluded. No turbidity was measured until the probe was approximately 15 inches off the tank bottom suggesting most of the solids suspended during the mixing had settled within 128 hours. For particles to have settled in that time, particle density, particle size, or both would have likely been larger than in either the data in Figure 35 or the sludge batch 6 simulant data previously discussed.

Alternatively, particle suspension may have been less than observed in previous SRNL testing.

Both the laboratory test with sludge batch 6 simulant and recent field settling data highlight the uncertainty inherent in predicting sludge particle behavior based on settling theory alone. To better reconcile theoretical sludge particle settling predictions with observed settling behavior in Tank 21, solids characterization and/or laboratory-scale settling testing using actual waste samples are recommended. The best data comes from Tank 21 itself, so it is also recommended to take full advantage of future mixing evolutions in Tank 21 to collect waste samples for laboratory study and field turbidity measurements to evaluate solid particle settling.

\subsection{CONCLUSIONS AND RECOMMENDATIONS}

Select flow rates and specific pump dimensions were provided by SRR to model pumps in Tanks 21 and 24. Literature results and previous research from Phase 1 and Phase 2 testing were used along with CFD models to determine blending times for Tank 21 and Tank 24 , and to ensure that sludge will not be entrained during transfers. A minimum 33 day settling time was assumed between transfers for both tanks, even though mixing of the sludge was assumed to occur. This requirement is implicit with respect to sludge entrainment during transfers.

Conclusions are as follows:

1) The blending time for a Sulzer pump operating at full speed in Tank 21 is 2 hours and 13 minutes, but may be longer if lighter fluids are added to heavier fluids.

2) The blending time for a Submersible Blender Pump operating in Tank 24 at the midheight of the maximum fluid level depends on $U_{0} d_{0}$. At $U_{0} d_{0}=4.85 \mathrm{feet}^{2} / \mathrm{second}$, the recommended blending time is 4.86 hours. At $U_{0} d_{0}=3.58 \mathrm{feet}^{2} / \mathrm{second}$, the recommended blending time is 6.58 hours. Blending times may be as much as ten times greater, or more, if water is added to a salt solution. This effect on blending times was not investigated for different density solutions, but as the densities of two different blended solutions converge, this effect is expected to be minimized.

3) Sludge will not be entrained by the Hazelton transfer Pump when it is installed 52.9 inches, or more, above the sludge layer. 
4) Sludge will not be entrained by the Tsurumi transfer Pump when the bottom plate of the pump is installed 9 inches, or more, above the sludge layer.

5) Based on theoretical calculations, particles in the density range of 2.5 to $5.0 \mathrm{~g} / \mathrm{mL}$ must be greater than $2-4 \mu \mathrm{m}$ in diameter to ensure they settle adequately in 30-60 days to meet the SWPF feed criterion ( $<1200 \mathrm{mg} / \mathrm{l}$ ).

6) Experimental tests with sludge batch 6 simulant and field turbidity data from a recent Tank 21 mixing evolution suggest that the solid particles have higher density and/or larger size than indicated by previous analysis of SRS sludge and sludge simulants.

Recommendations are as follows:

1. Perform additional analyses for different operating conditions of the transfer and blending pumps.

2. Validate blending times and transfer pump clearances in a full scale tank.

3. Evaluate blend time effects when adding less dense solutions to denser solutions, using further pilot scale research or measured data from a full scale tank.

4. Perform additional CFD models at different pump elevations and liquid levels, if required for operations.

5. Perform additional testing or CFD modeling to determine if transfer pumps can be lowered closer to the sludge layer, if required by SRR.

6. After pump operations are in process, an SRNL review of performance data is recommended to validate recommendations from this report for future CFD applications.

7. Tank 21 waste characterization, laboratory settling tests, and additional field turbidity measurements during mixing evolutions are recommended to better understand the potential risk for extended (> 60 days) settling times in Tank 21. 


\section{REFERENCES}

1. Leishear, R. A., Poirier, M. R., and Fowley, M. D., "SDI Blend and Feed Blending Pump Design Phase 1 (U)", Savannah River National Laboratory, SRNL-STI-201000054, March 2010, pp. 1-100.

2. Leishear, R. A., Poirier, M. R., and Fowley, M. D., "Blending Study for SRR Salt Disposition Integration: Tank $50 \mathrm{H}$ Scale-Modeling and Computer-Modeling for Blending Pump Design, Phase 2 (U)", Savannah River National Laboratory, SRNLSTI-2010-00151, May 2011, pp. 1-169.

3. Leishear, R. A., Poirier, M. R., Fowley, M. D., Lee, and S. Y., Steeper, T. J.., 2011, "Comparison of Experimental Results to CFD Models for Blending in a Tank Using Dual Opposing Nozzles", IMECE 2011-62042, International Mechanical Engineers Congress and Exposition, American Society of Mechanical Engineers, New York, New York, pp. 1-12.

4. Leishear, R. A., Fowley, M. D., Poirier, M. R., Lee, S. Y., and Steeper, T. J., 2011, "Blending Time and Velocity Variations During Blending in a Tank Using Dual Opposing Jets", IMECE2011-62116, International Mechanical Engineers Congress and Exposition, American Society of Mechanical Engineers, New York, New York, pp. 1-11.

5. Leishear, R. A., Fowley, M. D., Poirier, M. R., Lee, S. Y., Parkinson, K. S., and Steeper, T. J., 2011, "Incipient Sludge Mixing in Nuclear Waste Tanks During Salt Blending “, Waste Management 2011 Conference, Phoenix, AZ, Paper No. 11086, pp. 1-14.

6. Leishear, R. A., Fowley, M. D., Poirier, M. R., Steeper, T. J., 2010, "Cooling Coil Effects On Blending in a Pilot Scale Tank", AIChE Annual Conference, New York, New York, pp. 1-30.

7. Leishear, R. A., Poirier, Lee, S. Y., "Task Technical and Quality Assurance Plan for Tank 21 and 24 Blend and Feed Blending Study", Savannah River National Laboratory, SRNL-RP-2012-00083, pp. 1-14.

8. Ervin, R. C., "Pump Modeling for Tanks 21 and 24", Technical Task Request, U-TTRH-00019, Rev. 0, December 19, 2011, pp. 1-3.

9. Lee, S. Y. and Armstrong, B. W., "SDI CFD Modeling Analysis", Savannah River National Laboratory, SRNL-STI-2011-00025, April 2011, pp. 1-67.

10. R. A. Dimenna, S. Y. Lee, and D. A. Tamburello, "Advanced Mixing Models", SRNLSTI-2011-00026, Savannah River National Laboratory, February 2011, pp. 1-66.

11. J. Baldyga and J. R. Bourne, "A Fluid Mechanical Approach To Turbulent Mixing and Chemical Reaction, Part III Computational and Experimental Results for the New Micromixing Model", Chem. Eng. Commun., Vol. 28, 1984, pp. 259-281.

12. S. Y. Lee, R. A. Dimenna, R. A. Leishear, and D. B. Stefanko, "Analysis of Turbulent Mixing Jets in a Large Scale Tank", ASME Journal of Fluids Engineering, Volu 130, Number 1, 2008, p. 011104.

13. ANSYS FLUENT 6.3, September 2006.

14. R. K. Grenville, and J. N. Tilton, "A New Theory Improves the Correlation of Blend Time Data from Turbulent Jet Mixed Vessels", Trans. Inst. of Chem. Eng., Vol. 74, Part A., 1996, pp. 390-396.

15. W. P. Jones, and B. E. Launder, "The Prediction of Laminarization with a TwoEquation Model of Turbulence", Int. J. of Heat Mass Transfer, vol. 15, 1972, pp. 301314. 
16. I. C. Walton, "Eddy Diffusivity of Solid Particles in a Turbulent Liquid Flow in a Horizontal Pipe", AIChE J., vol. 41, no. 7, 1995, pp. 1815-1820.

17. R. H. Perry and C. H. Chilton, Chemical Engineers' Handbook, $5^{\text {th }}$ Ed., New York: McGraw-Hill, 1973.

18. M. R. Poirier, F. F. Fondeur, D. P. Lambert, David T. Hobbs, and S. D. Fink, "Particle Size of Simulated SRS Sludge, Actual SRS Sludge, and Monosodium Titanate", WSRC-TR-2003-00221, May 20, 2003. 